\title{
Should Continued Family Firms Face Lower Taxes Than Other Estates?
}

\author{
Volker Grossmann ${ }^{\dagger}$ and Holger Strulik \\ Leibniz Universitat Hannover, Discussion Paper No. 387
}

ISSN 0949-9962

First Version: February 2008. This Version: January 2009

\begin{abstract}
Taxes on inheritances may induce heirs to discontinue family firms. Because firm dissolution incurs transaction costs, a preferential tax treatment of transferred family businesses seems to be desirable from a macroeconomic viewpoint. The support of dynastic succession, however, entails also a cost on the economy if firm continuation by less able heirs prevents entry into entrepreneurship. Here, we investigate analytically and quantitatively the trade-off between transaction costs saved and creative destruction prevented. We find that a unique general equilibrium exists at which, depending on the institutional setup, low-ability heirs either abandon (Type 1) or continue (Type 2) a family business. A calibration of the model with German data suggests that preferential tax treatment of family firms has severe negative consequences on macroeconomic performance if it causes a threshold crossing from Type 1 to Type 2 equilibrium. It also reveals that the descendants of entrepreneurs that are caused to continue a business, always lose relative to their status in an economy without continuation-friendly tax policy.
\end{abstract}

Keywords: Bequest Taxation, Creative Destruction, Entrepreneurship, Family Firms, Preferential Tax Treatment.

JEL: H25, L26, J24.

\footnotetext{
${ }^{*}$ We are grateful to seminar participants at the CESifo Area Conference in Public Economics in Munich 2008 for helpful comments and suggestions, particularly to Volker Meier.

${ }^{\dagger}$ University of Fribourg; CESifo, Munich; Institute for the Study of Labor (IZA), Bonn. Address: Department of Economics, University of Fribourg, Bd. de Pérolles 90, CH-1700 Fribourg, Switzerland. E-mail: volker.grossmann@unifr.ch.

${ }^{\ddagger}$ University of Hannover, Wirtschaftswissenschaftliche Fakultät, Königsworther Platz 1, 30167 Hannover, Germany; Email: strulik@vwl.uni-hannover.de.
} 


\section{INTRODUCTION}

Taxation of inheritances or estates is under steady debate in many industrialized countries. On the one hand, proponents argue that taxing inheritances is an effective mean to "level the playing field", i.e. to mitigate wealth inequality and improve equality of opportunity. On the other hand, supporters of tax reduction or repeal argue that it provides disincentives to accumulate capital and retards work effort. ${ }^{1}$

Here we focus on one point that is always stressed in the inheritance tax debate, namely that taxes on inherited family firms impose a burden on the heirs that may induce them to discontinue the business. Business closures and the start up of new firms entail transaction costs, i.e. real efficiency losses without any gains elsewhere in the economy. It has been argued that, therefore, continuation of family firms is desirable from a macroeconomic viewpoint and should not be punished by the tax law. ${ }^{2}$

In many industrialized countries the tax law treats inherited firms preferentially or reforms in this direction are planned for the future. Already in 1994 the European Commission (1994) published its recommendations on the transfer of small and medium size enterprises where it reads "We want to encourage the Member States to adopt concrete and specific measures to prevent SME closures, which have an adverse effect on attempts to maintain and increase employment. [...] The Commission requests the Member States to ensure that family law, inheritance law and the payment of financial compensation cannot jeopardize the survival of the business [and to] reduce taxation on assets in the event of transfer by succession or by gift, provided that the heirs continue to operate the business." In 2006 the European Commission (2006) reviewed the implementation of its recommendations and concluded that 21 out of 25 states had either implemented the recommendation of reduced inheritance taxation or were planning an implementation for the future.

The high importance attributed to inheritance taxation of family firms stems from the recog-

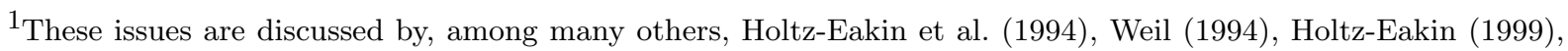
Kopczuk and Slemrod (2001), Gale and Perozek (2001) Holtz-Eakin and Marples (2001), and in a general equilibrium context by Laitner (2001) and Cagetti and de Nardi (2007). Gale and Slemrod (2001) provide a short survey over "rhetoric and economics in the estate tax debate" In a recent normative approach Farhi and Werning (2007) find that the optimal inheritance tax is progressive if future generations are directly valued in welfare maximization.

${ }^{2}$ This reasoning is somehow weakened by the fact that the current owner could (and in many cases does) take care of expected inheritance tax payments through life insurance so that there is no sudden liquidity constraint to bear for offsprings when they take over the business and face the tax burden. But the general argument that inheritances taxes may prevent firm continuation and cause transaction costs remains, of course, valid.
} 
nition that this institution is a quantitatively important determinant of employment, income per capita, and many other macroeconomic aggregates. In Germany, for example, about 85 percent of all firms in the manufacturing sector are family-owned and managed (BDI, 2006). The small and medium enterprises (SMEs) of the so called German "Mittelstand" encompasses 99 percent of all German companies and employs about 70 percent of the labor force. Many European countries (but not the U.S.) show similar characteristics. 99 percent of the European enterprises are SMEs. The average European SME employs 6 people and $66 \%$ of the European labor force are employed in SMEs (See European Commission, 2003, and Deutsche Bank, 2007.)

The business continuation argument shifts the discussion from the general pros and cons of inheritance taxation towards the specific tax treatment of one particular item, the family firm. Strictly speaking, the continuation argument cannot be used in order to generally justify inheritance tax cuts or the preferential tax treatment of inherited businesses. Instead, tax alleviation should be contingent on an action of the heirs, namely to continue the inherited firm. With respect to family firm friendliness we can thus differentiate between three possible tax schemes, equal treatment of all inherited wealth, preferential treatment of family firms, and preferential treatment of family firms contingent on their continuation.

A discussion of the three possible tax schemes is epitomized almost ideally by the current debate on inheritance taxes among legislature, jurisdiction, and business associations in Germany. According to the current law, real estates and businesses - irrespective of their continuation receive a preferential treatment vis-à-vis other forms of bequests. Because this procedure does not conform to the principle of equality the Federal Constitutional Court has ruled against it. This implies that the current tax system operates at most until 2009. If there is no tax reform until then, family firms will be treated like other bequests. Yet, the Bundestag has just (in December 2007) launched a tax reform that simultaneously abolishes the general preferential treatment of family firms and establishes major tax alleviation for businesses that are continued for at least 15 years by the heirs.

Preferential tax treatment of continued family firms, however, may also incur a cost on society. While the founder of a family business is almost by definition endowed with high entrepreneurial skills this is not necessarily true for his or her heirs. Unlike financial wealth, management skills cannot be inherited perfectly. Given a possibly small but inevitably positive probability that heirs do not inherit the entrepreneurial spirit and the management skills of their parents, 
management abilities, like other personal characteristics, regress towards the mean (Galton, 1877, Mulligan, 1999). On average and over the long-run, heirs of family firms will have just average skills to run the business and probably underperform vis-à-vis new entrants who are by self selection into entrepreneurship - more likely to be endowed with high entrepreneurial skills.

While there are also good reasons to believe that heirs of family firms are endowed with particular management traits (tacit firm-specific knowledge and longer planning horizons, for example), the recent empirical evidence suggests that the negative regression-to-the-mean effect dominates. Comparing publicly traded businesses it has been found that heir-controlled firms underperform relative to those managed by unrelated CEOs. This is shown by Morck et al. (1998), Perez-Gonzalez (2006), Villalonga and Amit (2006), Bloom and van Reenen (2007), and Bennedsen et al. (2007) for US American, British, Canadian, Danish, French, and German firms.

A continuation-friendly tax policy that causes low-ability heirs to continue a family business has direct and indirect repercussion on the macroeconomy. If managing ability complements factor input, which seems to be a natural characteristic of managing qualities, low-ability heirs invest less and employ less workers than their high-ability counterparts. In short, they run inefficiently small businesses. A second, indirect effect on efficiency occurs if the presence of low-ability descendants of firm owners blocks entry into entrepreneurship of high-ability descendants of workers. In this case, a continuation-friendly tax policy reduces aggregate total factor productivity (TFP) and through this channel probably not only current GDP per capita but also economic growth. It slows down the Schumpeterian process of creative destruction. Finally, firm continuation may have a negative "third generation" effect on welfare that occurs when low-ability heirs invest little or nothing, live off the capital stock of the inherited firm instead, and transfer small wealth to their own offspring.

It is our impression that these negative repercussions of firm continuation are largely overlooked in the inheritance tax debate. This does, of course, not necessarily imply that fostering firm continuation is a bad idea. Firm continuation may still be worthwhile because of the saved transaction costs through prevented exit and entry. A trade-off exists and the question is which effect dominates. The purpose of the present paper is thus to investigate whether lower inheritance taxes for family firms are efficiency-enhancing or whether they are reflecting family values, which are harmful for aggregate economic performance and welfare. 
In order to solve this problem we propose a simple general equilibrium model with endogenous exit and entry of heterogeneous family-owned firms and inheritance taxation. We model the decision of descendants of firm owners whether to operate the inherited firm or to sell it and become a worker. Descendants of workers decide whether to become entrepreneur or worker. Entrepreneurs choose the amount of investment and bequeath the firm to their offspring. With this dynastic business transfer we intend to capture the revealed preferences of many firm owners, i.e. the desire to ensure survival and family control of their firm. Workers, by contrast, choose the amount of their bequests through foregone life-time consumption. The fact that individuals differ by provenance, i.e. origin from worker- or entrepreneur-households, by inherited wealth, and by entrepreneurial talent drives the heterogeneity of firms and the performance of the macroeconomy.

In the analytical part of the paper we show that there exists a unique general equilibrium of the model economy, which assumes one of two possible types. In a Type 1 equilibrium low-ability heirs of family firms sell the business and exit the market immediately, in a Type 2 equilibrium low-ability heirs continue the business unless they have inherited it from a parent who was also of low ability. We show how the threshold separating Type 1 from Type 2 depends, among other things, on inheritance tax arrangements and we investigate performance of the economy at the two types of equilibria.

We then continue by calibrating the model with German data and investigate numerically how alternative, currently debated inheritance tax reforms affect the performance of the economy with respect to income per capita, TFP and other economic indicators. We also show the impact of the proposed reforms on utility of the different groups in society and on aggregate welfare.

Our model shares some elements with Caselli and Gennaioli (2006) who also investigate firms where ownership and control are passed from one generation to the other. They show that dynastic management reduces total factor productivity if the heirs have little talent and use this result to explain cross-country differences in TFP. The incidence of family firms is explained by weak institutions and underdeveloped financial markets. As a result, family firms are predicted to be more prevalent in less developed countries from which the difference in TFP across countries derives. With contrast, we investigate family firms in fully industrialized countries with strong institutions and developed financial markets. Family values motivate entrepreneurs to pass on their firm to their offspring and the interaction of tax legislation, transactions cost, and wealth 
inequality determines whether the heirs continue the business. ${ }^{3}$

\section{THE MODEL}

2.1. The Population. We consider an economy populated by a unit mass of families, indexed by $i \in[0,1]$. Families are intergenerationally linked and conceptualized as dynasties whereby we assume for simplicity that each parent generation has one child. In each period $t=0,1,2, \ldots$ there is one generation of each dynasty economically active, either as a worker or as an entrepreneur. The number of entrepreneurs $\left(n_{t}\right)$ and the number of workers $\left(1-n_{t}\right)$ in the economy is generally endogenous and predetermined only for the initial period.

From period one onwards economic agents have to make a career decision depending on kind and magnitude of their inherited wealth and their endowment with entrepreneurial skills (in short "ability"). Specifically, we assume that the ability to manage a firm is either high or low, i.e. ability of the member of family $i$ who is economically active in period $t$ is given by $a_{t}(i) \in\left\{a^{L}, a^{H}\right\}, a^{L}<a^{H}$. Like wealth, managerial ability may be inherited. Although the recent empirical literature provides little support for an intergenerational transfer of talent (see the Introduction) it is nevertheless useful to control for this possibility. This way, the model takes into account that family firms may be transferred together with the ability to manage them, an argument that could be put forward by supporters of inheritance tax relief. Inheritance of ability does not necessarily have to be conceptualized as the transmission of a "manager-gene". It may also include the transfer of tacit management knowledge within the family. In modelling ability inheritance we follow Caselli and Gennaioli (2006). Specifically, we assume that there is a fraction $\lambda$ of high-ability individuals in the population and that the correlation coefficient of parent's and children's ability is given by $\mu, 0 \leq \mu<1$. A stationary distribution of ability requires then that the probability to inherit one's parent high ability is $p^{H}=\lambda+\mu-\lambda \mu$ whereas the probability to inherit low ability is $p^{L}=1-\lambda+\lambda \mu$.

2.2. Dynasties. Dynasties are linked through intentional transfers of wealth. A family member $i$ of generation $t$ has preferences over consumption $c_{t}(i)$ and the net amount bequeathed to the

\footnotetext{
${ }^{3}$ Caselli and Gennaioli investigate a much richer wealth distribution than the present paper. Since our main arguments are based on efficiency considerations we impose a very stylized distribution of wealth in order to obtain our main results analytically hoping that distributional issues are of second order for efficiency outcomes. How bequests affect the wealth distribution is an interesting aspect in itself which is addressed by Laitner (2001), Heer (2001), Cagetti and de Nardi (2006, 2007), and Bossmann, Kleiber and Wälde (2007). The link between entrepreneurship, savings, and wealth distribution is also investigated by Quadrini (1999) and Gentry and Hubbard (2004).
} 
offspring, reflecting a "joy-of-giving" bequest motive (Andreoni, 1989). Taking an inheritance tax at rate $\tau$ into account the net bequest $b_{t}^{\text {net }}$ enters a quasi-linear utility function together with consumption.

$$
U_{t}(i)=c_{t}(i)+v\left(b_{t}^{\text {net }}(i)\right),
$$

where $v^{\prime}>0, v^{\prime \prime}<0$. The elasticity of marginal utility from bequests is constant and denoted by $\eta \in(0,1]$. Quasi-linearity of the utility function allows us to solve the model analytically and to work out important mechanisms. The form of bequests is conditional on occupation. For workers, bequests consist of foregone life-time consumption whereas for entrepreneurs they consist of the capital stock of their firm. Thus, the prospect that the firm remains in the ownership of the family serves as a second motive (besides making profits) for investment of entrepreneurs. ${ }^{4}$

Given that capital depreciates at rate $\delta \in[0,1)$, an entrepreneur $i$ in $t$ bequeaths an amount $(1-\delta) k_{t}(i)$ of the capital stock. We assume that heirs do not assign a particular non-pecuniary value to family firms implying that they sell an inherited firm whenever this appears to be financially worthwhile. Depending on provenance and occupation individuals in our modelsociety can be classified into four types:

- heirs of entrepreneurs who continue a family business

- heirs of entrepreneurs who sell an inherited firm and become workers

- heirs of workers who start up a new enterprise

- heirs of workers who continue to be workers.

In principle, each type can be assumed by high and low-ability individuals but talented heirs (endowed with ability $a^{H}$ ) have an advantage in continuing a family firm vs. untalented heirs and talented offspring of workers have an advantage in establishing a new enterprise vs. their untalented counterparts.

2.3. Investment and Firm Sale. If a member of dynasty $i$ inherits a firm and remains entrepreneur, he decides upon how much to invest into that firm. When he invests $z_{t}(i)$ the capital input is given by

$$
k_{t}(i)=(1-\delta) k_{t-1}(i)+z_{t}(i)
$$

\footnotetext{
${ }^{4}$ The view that the incidence of family firms originates from family values is supported by the evidence compiled
} in Bertrand and Schoar (2006). 
If he prefers to give up the inherited firm, the capital stock $(1-\delta) k_{t-1}(i)$ is sold to the world market at a price $q \in(0,1]$ per unit of capital. The price $q$ may be smaller than one because capital is attached to the specific environment of the firm and is less valuable for an outside buyer than within the particular firm. Alternatively, one may think of costs to deinstall capital and install it elsewhere. In general, $q$ is an inverse measure of transaction costs associated with the sale of a firm, i.e., a low value of $q$ indicates large transaction costs per unit of capital. Because transaction costs are modelled as an extra deprivation of capital through sale, they imply foregone output and impose a real efficiency loss on the economy, a loss that would not occur if the firm were continued. ${ }^{5}$

If a descendant of a worker decides to become entrepreneur, he has to incur a fixed cost $\bar{k} \geqslant 0$ so that after investing $z_{t}(i)$ the amount of capital employed in the production process of a newly founded firm $i$ in $t$ is given by

$$
k_{t}(i)=z_{t}(i)-\bar{k}
$$

Here the parameter $\bar{k}$ stands as a catch all for startup costs as well as costs stemming from liquidity constraints experienced by entrants because they cannot use an inherited firm as collateral. Fonseca, Michaud and Sopraseuth (2007), show that indices for startup costs and liquidity constraints are usually positively correlated across West European countries.

Investments are made in the beginning of the period. We consider a small open economy in an environment with developed financial markets and internationally mobile capital. Simplifying we assume that there are no borrowing costs besides $\bar{k}$ and that the desired capital stock can be financed at an internationally given interest rate, which is set to zero. Because our article is an investigation of the continuation problem of family firms and not of international tax competition, we exclude the possibility of tax avoidance through firm relocation. For that purpose we assume that owners of family firms who consider to escape inheritance taxation have to move their residence along with their firm (in order to supervise production) and that mobility costs, which may involve mental and social costs of moving abroad, are sufficiently high so that entrepreneurs prefer to stay at home.

\footnotetext{
${ }^{5}$ We discuss the possibility of external management in the Appendix and, briefly, in the Conclusion.
} 
2.4. Production. Output produced by an entrepreneur of family $i$ in period $t$ is determined by a Cobb-Douglass production function

$$
y_{t}(i)=a_{t}(i) l_{t}(i)^{\alpha} k_{t}(i)^{1-\alpha}
$$

$0<\alpha<1$, where $l_{t}(i)$ is labor input and $k_{t}(i)$ is capital input. Ability of entrepreneurs complements capital and labor inputs and operates like a measure of total factor productivity. An entrepreneur of high ability $\left(a_{t}(i)=a^{H}\right)$ produces more output for a given combination of inputs than a less able one.

Workers supply one unit of labor of identical quality to a perfect labor market and receive a wage $w_{t}$. Entrepreneurs are the residual claimants to income net of wage payments. Firms are price-takers and output prices are normalized to one. Thus earnings of an entrepreneur $i$ are given by

$$
\pi_{t}(i)=a_{t}(i) l_{t}(i)^{\alpha} k_{t}(i)^{1-\alpha}-w_{t} l_{t}(i)
$$

2.5. Government. The government levies proportional taxes on inheritances and redistributes the revenue in form of lump-sum transfers $T_{t}$. The government budget is balanced in each time period. In order to investigate our main policy problem we allow the taxes to depend on the type of asset inherited. The tax rate is

- $\tau_{k} \in[0,1)$ for descendants of firm owners who continue the family business.

- $\tau_{s} \in[0,1)$ for descendants of firm owners who sell the family firm, $\tau_{s} \geq \tau_{k}$.

- $\tau_{b} \in[0,1)$ for descendants of workers.

Let $b_{t}(i)$ denote the bequest of an individual $i$ in $t$. Depending on the relevant tax rate, $\tau \in\left\{\tau_{k}, \tau_{s}, \tau_{b}\right\}$, the after-tax bequest is given by

$$
b_{t}^{\text {net }}(i)=(1-\tau) b_{t}(i)
$$

In many countries, at first glance, the tax law suggests $\tau_{k}=\tau_{s}=\tau_{b}$. However, the effective tax rate applied to the capital stock of an inherited firm depends on institutional depreciation rules. If the tax treatment allows faster depreciation than the one physically taking place (i.e., the tax law allows the book value of the capital of a firm to depreciate at a higher rate than $\delta$ ), then in effect $\tau_{k}<\tau_{b}$. An effectively lower $\tau_{k}$ follows also from the deferral of tax payments for inherited family businesses which is permissable in many European countries and in the U.S. 
The legislator's underlying motivation for establishing a preferential tax treatment of inherited business capital is possibly not to privilege the heirs of firm owners but to foster firm continuation by alleviating the succession problem. Thus, a more sensible, fine-tuned tax policy consists of a preferential treatment of inherited family firms contingent on the continuation of the business. In some countries such a policy is already in place and in many others movements in this direction are high on the policy agenda. This motivates our assumption of a third tax rate $\tau_{s}$ that applies when an inherited firm is sold, $\tau_{s} \geq \tau_{k}$.

Arguments in favor of such tax relief for continued family businesses are captured by two elements in our model. Continued firms entail no startup costs $\bar{k}$ and the value of capital is not diminished in a process of firm dissolution (no sale of capital at price $q<1$ ). Because the continuation of family firms prevents these agency- and transaction costs, i.e. real efficiency losses of the economy, it may be desirable from a macroeconomic viewpoint and a preferential tax treatment seems to be worthwhile. However there is also an efficiency argument speaking against tax allowances for continued firms. ${ }^{6}$

The trade off occurs because ability is transferred imperfectly between generations $(\mu<1)$. Motivated by a preferential tax treatment some less able heirs may be inclined to continue a family business. As explained above, entrepreneurs of low ability make inferior use of factor inputs and reduce efficiency of the economy. The negative effect is amplified further if the presence of less able heir-managers blocks entry of highly able descendants of workers. In that case the survival of low-ability firm owners reduces the number of active high-ability entrepreneurs. In other words, a preferential tax treatment of family firms may slow down the Schumpeterian process of creative destruction. The investigation of the trade off between transaction costs saved and creative destruction prevented is at the center of the following discussion of the effects and desirability of alternative inheritance tax schemes.

\section{Career Choices}

3.1. Entrepreneurs. Consider a member of family $i$ with ability $a_{t}(i)$ inheriting a firm with $(1-\delta) k_{t-1}(i)$ units of capital (being equal to the tax base) who continues the family business and invests $z_{t}(i)$. His consumption is given by $c_{t}(i)=\pi_{t}(i)-z_{t}(i)-\tau_{k}(1-\delta) k_{t-1}(i)+T_{t}$. When he retires or dies he leaves an amount $(1-\delta) k_{t}(i)$ of productive capital in the family firm, which

\footnotetext{
${ }^{6}$ Our discussion focusses on efficiency arguments and largely neglects distributional issues.
} 
he bequeaths to his offspring. Inserting (2) and (5) into consumption, we see that utility (1) is maximized subject to

$$
\begin{aligned}
c_{t}(i) & =a_{t}(i) l_{t}(i)^{\alpha} k_{t}(i)^{1-\alpha}+\left(1-\tau_{k}\right)(1-\delta) k_{t-1}(i)+T_{t}-w_{t} l_{t}(i)-k_{t}(i), \\
b_{t}^{n e t}(i) & =\left(1-\tau_{k}\right)(1-\delta) k_{t}(i),
\end{aligned}
$$

where we implicitly assume that entrepreneurs believe that the firm is continued, i.e., that tax rate $\tau_{k}$ applies. ${ }^{7}$

An entrepreneur with ability $a_{t}(i)$ who operates a newly founded firm and who has received a bequest $b_{t-1}(i)$ from his parent, a worker, maximizes utility subject to

$$
c_{t}(i)=a_{t}(i) l_{t}(i)^{\alpha} k_{t}(i)^{1-\alpha}+\left(1-\tau_{b}\right) b_{t-1}(i)+T_{t}-w_{t} l_{t}(i)-k_{t}(i)-\bar{k},
$$

and (8), where we used (3) and (5) to obtain (9).

Entrepreneurs maximize utility through the optimal choice of employment of labor $l_{t}(i)$ and capital $k_{t}(i)$. It is easy to check that an interior solution requires that $w_{t}>(1-\alpha)^{\frac{1-\alpha}{\alpha}} \alpha\left(a^{H}\right)^{1 / \alpha} \equiv$ $\underline{w}$. We focus on this case throughout. Inserting (7), (8), and (9), respectively, in (1), stating the first order conditions, and solving for factor inputs we obtain ${ }^{8}$

$$
\begin{aligned}
& k_{t}(i)=\frac{\left[\left(1-\tau_{k}\right)(1-\delta)\right]^{\frac{1-\eta}{\eta}}}{\left(1-(1-\alpha)\left(\frac{\alpha}{w_{t}}\right)^{\frac{\alpha}{1-\alpha}} a_{t}(i)^{\frac{1}{1-\alpha}}\right)^{\frac{1}{\eta}}} \equiv \tilde{k}\left(a_{t}(i), w_{t}, \tau_{k}\right), \\
& l_{t}(i)=\left[\frac{\alpha \cdot a_{t}(i)}{w_{t}}\right]^{\frac{1}{1-\alpha}} \tilde{k}\left(a_{t}(i), w_{t}, \tau_{k}\right) \equiv \tilde{l}\left(a_{t}(i), w_{t}, \tau_{k}\right) .
\end{aligned}
$$

Inspection of the solution shows that the size of an inheritance $\left(k_{t-1}\right.$ or $b_{t-1}$, respectively) does not affect the choice of factor inputs, i.e. the size of the family firm. This outcome is a consequence of the assumed constant marginal utility from consumption. It prevents that lucky dynasties for which nature draws several $a^{H}$ 's after another amass disproportionate wealth and firm sizes. This way the range of possible types of dynasties is finite and an analytical solution of the equilibrium is possible. ${ }^{9}$ The size of a bequest will be "only" responsible for the decision

\footnotetext{
${ }^{7}$ As will become apparent for this to be true it is sufficient to assume that entrepreneurs believe that their offspring has high entrepreneurial ability. The assumption is not critical for the main results.

${ }^{8}$ Also recall $v(b)=(1-\eta)^{-1} b^{1-\eta}$ for $\eta \neq 1$ and $v(b)=\ln b$ otherwise.

${ }^{9}$ The simplifying assumption entails the opportunity cost of a less rich wealth distribution. This cost seems to be acceptable because we focus on the problem how inheritance taxation affect efficiency of an economy. For efficiency, the distribution of wealth is possibly of second order compared to the viability of low-ability entrepreneurs and the transaction costs of firm dissolution and establishment.
} 
to continue an inherited firm or not.

The size of the inheritance tax $\tau_{k}$, however, may matter for the size of firms because it affects the current firm owner's desire to leave bequests and through this channel affects investment and capital accumulation. Magnitude and sign of the effect of higher taxes are generally ambiguous. On the one hand, a substitution effect reduces the incentive to invest. One the other hand, there is also a wealth effect because higher taxes reduce the net amount inherited by offsprings. For $\eta=1$, the wealth effect exactly counterweighs the substitution effect and taxation does not affect factor inputs of a family firm. If $\eta<1$, the substitution effect dominates and higher taxes reduce the incentive to invest into family businesses. Allowing for $\eta<1$ we take a frequently heard anti-inheritance tax argument into account (Holtz-Eakin, 1999, Prescott, 2006). Since $\eta \leq 1$ seems to be supported empirically, and in order to limit case differentiation, we ignore the third possibility of $\eta>1$, which would imply that higher capital taxes trigger higher investments (but see Uhlig and Yanagawa, 1996).

Finally, the size of a firm, irrespective of whether inherited or not, depends on labor costs and the ability of its owner-manager. Inspection of (10a) and (10b) shows that factor demand is inversely related to the wage rate $w_{t}$, an outcome that reflects the neoclassical shape of the production function. Inspection shows also that less able entrepreneurs lead smaller firms. Other things equal, they prefer to install less machines and employ less workers. This outcome reflects the complementarity of managerial skills and factor inputs.

3.2. Workers. A worker $i$ who sells an inherited firm consumes

$$
c_{t}(i)=w_{t}+\left(q-\tau_{s}\right)(1-\delta) k_{t-1}(i)+T_{t}-b_{t}(i) .
$$

If the worker is the offspring of a worker, he consumes

$$
c_{t}(i)=w_{t}+\left(1-\tau_{b}\right) b_{t-1}(i)+T_{t}-b_{t}(i) .
$$

From utility maximization of workers we obtain that an optimal bequest requires $v^{\prime}\left(b_{t}^{\text {net }}(i)\right)(1-$ $\left.\tau_{b}\right)=1$, where $b_{t}^{\text {net }}(i)=\left(1-\tau_{b}\right) b_{t}(i)$. Thus, irrespective of social provenance a worker bequeaths

$$
b_{t}(i)=\left(1-\tau_{b}\right)^{\frac{1-\eta}{\eta}} \equiv \bar{b}\left(\tau_{b}\right)
$$

As for entrepreneurs, there is no long-run path dependency of wealth within dynasties since 
bequests do not depend on inheritances.

3.3. Exit. Heirs of family firms abandon the business if they can enjoy higher utility as a worker (and living off the receipts for the sold firm). Technically they compare utility (1) for (7), (8), (10a) and (10b) with utility (1) for (11) and (13). In conclusion, a member of family $i$ sells an inherited firm in period $t$ if and only if

$$
g\left(a_{t}(i), w_{t}, \tau_{k}\right)+\Delta(1-\delta) \cdot \tilde{k}\left(a_{t-1}(i), w_{t-1}, \tau_{k}\right)<w_{t}+B\left(\tau_{b}\right)
$$

where

$$
\begin{gathered}
\Delta \equiv 1-q+\tau_{s}-\tau_{k}, \quad B\left(\tau_{b}\right) \equiv \frac{\eta}{1-\eta} \cdot \bar{b}\left(\tau_{b}\right), \\
g\left(a_{t}(i), w, \tau_{k}\right) \equiv \frac{\eta}{1-\eta} \cdot\left(\frac{\left(1-\tau_{k}\right)(1-\delta)}{1-(1-\alpha)\left(\frac{\alpha}{w_{t}}\right)^{\frac{\alpha}{1-\alpha}} a_{t}(i)^{\frac{1}{1-\alpha}}}\right)^{\frac{1-\eta}{\eta}} .
\end{gathered}
$$

Here, $B$ is the net utility received from making a bequest as a worker $\left(v\left(b^{n e t}\right)-b\right)$. Adding to it the income of a worker $(w)$ gives us the right hand side of (14). Likewise, the first term on the left hand side, $g\left(a, w, \tau_{k}\right)$, is the sum of an entrepreneur's income $(\pi)$ and net utility from passing on the firm $\left(v\left(b^{\text {net }}\right)-k\right){ }^{10}$

The second term on the left hand side of (14) sums up the missing items. The parameter $\Delta$ can be conceptualized as the continuation value of a unit of business capital. If there are no transaction costs of firm dissolution $(q=1)$ and no tax advantage of keeping the firm $\left(\tau_{k}=\tau_{s}\right)$, then the continuation value is zero. Otherwise $\Delta$ is strictly positive and increasing in transaction costs $(1-q)$ and the tax advantage $\left(\tau_{s}-\tau_{k}\right)$. Whenever $\Delta>0$, the incentive to continue a family business increases with the size of the bequest. Note that this implies that both high-ability and low-ability heirs are more inclined to continue a family business if they have received it from a high-ability parent because, as explained above, high-ability entrepreneurs lead large firms.

Because highly able entrepreneurs generate more profits, they get more utility out of their entrepreneurship than their low-ability counterparts. To verify this observe that $g(\cdot)$ is strictly increasing in ability $a_{t}(i)$. Running a firm is also, ceteris paribus, more worthwhile if the wage rate $w_{t}$ is low, i.e. cash flow and profits are high, and if the inheritance tax rate $\tau_{k}$ is low, i.e.

\footnotetext{
${ }^{10}$ For the special case of $\eta=1$ we have to redefine $B \equiv \ln \left(1-\tau_{b}\right)$ and $g\left(a, w, \tau_{k}\right) \equiv \ln \left[\left(1-\tau_{k}\right)(1-\delta)\right]-$ $\ln \left(1-(1-\alpha)\left(\frac{\alpha}{w}\right)^{\frac{\alpha}{1-\alpha}} a^{\frac{1}{1-\alpha}}\right)$.
} 
utility experienced from bequeathing the firm to the offspring is high.

3.4. Entry. Now consider the entry decision of descendants of workers. They compare utility (1) for (8), (9), and (10a) with utility (1) for (12) and (13). Thus, an offspring of a worker-parent $i$ becomes an entrepreneur if and only if

$$
g\left(a_{t}(i), w_{t}, \tau_{k}\right)-\bar{k} \geq w_{t}+B\left(\tau_{b}\right)
$$

As above, the right hand side of (15) comprises, for a worker, income plus net utility from making a bequest and the first term on the left hand side is the analogous expression for an entrepreneur. With contrast to heirs of family firms, heirs of workers cannot experience any continuation value from keeping a business. Instead they have to bear startup costs $\bar{k}$. Not surprisingly, higher entry costs mitigate the incentive to enter. Workers are also less inclined to enter if wages are high because then, ceteris paribus, income of entrepreneurs is low and labor income of workers is high. Inheritance taxes have, with respect to their tax base, opposing effects on entry. A higher tax rate applied to the bequests of descendants of workers $\left(\tau_{b}\right)$ raises the incentive to enter, whereas a higher tax rate on bequeathed firms $\left(\tau_{k}\right)$ reduces it.

\section{Equilibrium Analysis}

At a steady-state, the number of exiting and entering firms coincide. To avoid only mildly interesting case distinctions, we focus on parameter constellations such that there is entry and exit in equilibrium. Low-ability descendants of workers, however, will never enter in entrepreneurship. To see this, conclude from $\Delta \geq 0$ and $\bar{k} \geq 0$ that according to (14) and (15) the incentive to set up a new firm is never larger than the incentive to continue an inherited firm for any given type of ability. Thus, in an equilibrium with exit of low-ability heirs of family firms there cannot be simultaneously entry of low-ability heirs of workers.

While low-ability types never enter in equilibrium, high-ability types enter until the utility from setting up and running a business is driven down to the utility from wage work. This is the case when the wage equalizes utility from entering and staying out, i.e. the steady-state wage rate $w^{*}$ fulfils

$$
g\left(a^{H}, w^{*}, \tau_{k}\right)-\bar{k}=w^{*}+B\left(\tau_{b}\right)
$$

The equilibrium wage $w^{*}$ is unique because $g\left(a^{H}, w, \tau_{k}\right)$ is strictly decreasing in the wage rate whereas the utility from wage work is strictly increasing. Figure 1 visualizes the equilibrium. 
Utility from running a firm increases with ability and decreases with the inheritance tax. In the figure, higher ability $a^{H}$ and lower taxes on firms $\tau_{k}$ shift the $g\left(a^{H}, w, \tau_{k}\right)$ curve upwards and the resulting higher demand and lower supply of wage work leads to an equilibrium at a higher wage rate. Likewise, higher start up costs $\bar{k}$ and lower inheritance taxes $\tau_{b}$ (implying higher net utility from bequeathing $B$ ) shift the $w+B\left(\tau_{b}\right)+\bar{k}$ curve upwards. A career as entrepreneur becomes less attractive and higher supply and lower demand of workers are balanced by a smaller equilibrium wage.

Figure 1: Entry Decision and Equilibrium Wage

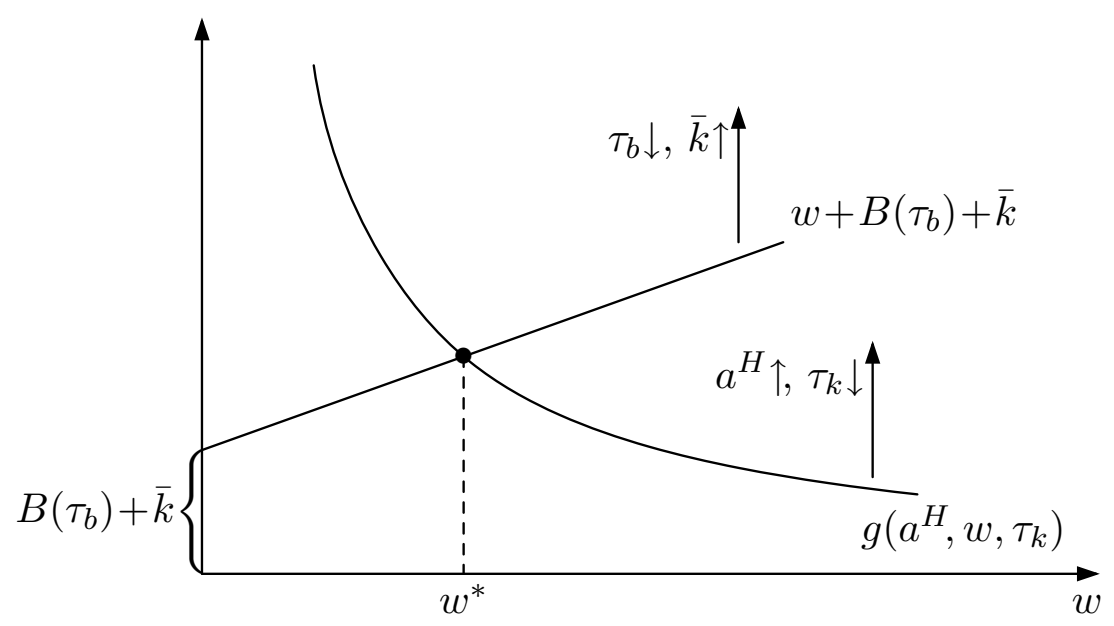

Finally, there has to be exit. According to the exit decision rule (14) there will be exit in equilibrium if

$$
g\left(a^{L}, w^{*}, \tau_{k}\right)+\Delta(1-\delta) \tilde{k}\left(a^{L}, w^{*}, \tau_{k}\right)<w^{*}+B\left(\tau_{b}\right) .
$$

Assumption A1 ensures that low-ability descendants of entrepreneurs exit if also their parent had low ability. It is maintained throughout.

Interestingly, assumption A1 leaves scope for two structurally different equilibria, which can alternatively occur depending on the numerical specification of the model's parameters, i.e. depending on the specification of technologies, preferences, institutions, and, most importantly, the underlying inheritance tax policy. At the first equilibrium low-ability heirs of family firms always exit implying that only firms led by high-ability entrepreneurs are participating in the market. At the alternative equilibrium low-ability heirs of family firms continue the business if their parent was of high ability. 
Intuitively, the likelihood that an economy is situated at the second equilibrium is high when the continuation value $\Delta$ is large. As explained, this is the case if either transaction costs entailed by the sale of capital are high (low $q$ ) or if the government rewards a high tax advantage for continued family firms, i.e. if $\tau_{s}-\tau_{k}$ is large. In other words, if transactions costs are low and/or the tax advantage is absent or low, then the continuation value is small and low-ability heirs are more inclined to sell the firm and exit immediately irrespective of their parents' ability. This reasoning implies that there exists a threshold for the continuation value below which there are only high-ability entrepreneurs present and above which the market is shared by entrepreneurs of high and low-ability.

Before we show that the intuition is indeed true, to close the model note that total labor demand equals supply in equilibrium; i.e., $\int_{0}^{n_{t}} l_{t}(i) d i=1-n_{t}$. Let $n^{L}$ and $n^{H}$ denote the mass ("number") of firms led by entrepreneurs of type $a^{L}$ and $a^{H}$, respectively. Using (10b) and omitting the time index, labor market clearing implies

$$
n^{L}\left[\tilde{l}\left(a^{L}, w, \tau_{k}\right)+1\right]+n^{H}\left[\tilde{l}\left(a^{H}, w, \tau_{k}\right)+1\right]-1=0 .
$$

We denote the wage rate which is implicitly defined in (17) by $\tilde{w}\left(n^{L}, n^{H}, \tau_{k}\right)$. It is strictly increasing in both $n^{L}$ and $n^{H}$ (to see this, recall that $\tilde{l}\left(a, w, \tau_{k}\right)$ is decreasing in $w$ ). A larger number of entrepreneurs of either kind raises labor demand and reduces labor supply; thus, the equilibrium wage rate rises. Moreover, the effect of an increase in $\tau_{k}$ on $\tilde{w}$ is negative if $\eta<1$ and zero if $\eta=1$. The following proposition specifies the threshold value for $\Delta$ which determines the type of equilibrium and the number of participating firms of each type. (All proofs are relegated to the Appendix).

Proposition 1. There is a threshold value

$$
\hat{\Delta} \equiv \frac{w^{*}+B\left(\tau_{b}\right)-g\left(a^{L}, w^{*}, \tau_{k}\right)}{(1-\delta) \tilde{k}\left(a^{H}, w^{*}, \tau_{k}\right)}
$$

such that in long-run equilibrium the following holds: ${ }^{11}$

(i) For $\Delta<\hat{\Delta}$, there are only high-ability entrepreneurs in the market (i.e., $n^{L}=0$ ). The number of firms, $n=n^{H}$, is given by $\tilde{w}\left(0, n^{H}, \tau_{k}\right)=w^{*}$, with $w^{*}$ as defined by (16). In each period, all firm-heirs who have drawn a low ability, i.e., $\left(1-p^{H}\right) \cdot n^{H}$ firms, exit. (Type 1 equilibrium.)

\footnotetext{
$\overline{{ }^{11} \text { We will not }}$ consider the knife-edge (non-generic) case where $\Delta=\hat{\Delta}$.
} 
(ii) For $\Delta>\hat{\Delta}$, there are $n^{L}=\left(1-p^{H}\right) \cdot n^{H}>0$ firms led by low-ability entrepreneurs in the market and the number of high-ability entrepreneurs, $n^{H}$, is given by $\tilde{w}\left(\left(1-p^{H}\right) \cdot n^{H}, n^{H}, \tau_{k}\right)=$ $w^{*}$. In each period, all descendants of low-ability entrepreneurs who have low ability themselves, i.e., $p^{L} \cdot n^{L}$ firms, exit. (Type 2 equilibrium.)

Corollary 1. A long-run equilibrium for the composition of firms exists and is unique.

The next corollary shows how preferential tax treatment of continued businesses affects the type of equilibrium assumed by an economy.

Corollary 2. Starting from a Type 1 equilibrium where $\tau_{k}=\tau_{s}$, introducing a sufficiently pronounced preferential tax treatment of continued businesses $\left(\tau_{s}>\tau_{k}\right)$ by raising tax rate $\tau_{s}$ induces a transition to a Type 2 equilibrium.

It is interesting to examine in which type of equilibrium there are more firms led by high-ability entrepreneurs. Using (17), this question is addressed in the next proposition.

Proposition 2. The number of firms led by high-ability entrepreneurs in an equilibrium of Type 1 and Type 2 are given by

$$
\begin{aligned}
& n^{H}=\frac{1}{\tilde{l}\left(a^{H}, w^{*}, \tau_{k}\right)+1} \equiv \hat{n}^{H 1}, \\
& n^{H}=\frac{1}{\left(1-p^{H}\right) \tilde{l}\left(a^{L}, w^{*}, \tau_{k}\right)+\tilde{l}\left(a^{H}, w^{*}, \tau_{k}\right)+2-p^{H}} \equiv \hat{n}^{H 2},
\end{aligned}
$$

respectively, where $w^{*}$ is given by (16). In a Type 2 equilibrium there are more firms in total but less firms led by high-ability entrepreneurs than in a Type 1 equilibrium $\left(\hat{n}^{H 2}<\hat{n}^{H 1}\right)$.

The result in Proposition 2 implies that tax incentives for continuing family firms, possibly established with the intention to save transaction costs entailed by firm dissolution and startup, have a negative side-effect on performance of the economy. If the economy assumes a Type 2 equilibrium as a consequence of preferential tax treatment, firms are continued although heirs have low entrepreneurial ability. This continuation deters entry of high-ability descendants of workers such that the equilibrium number of high-ability entrepreneurs is lower than without such tax incentives. Crowding out of high-ability entrepreneurs, however, is not perfect because staying low-ability heirs run smaller businesses due to the managerial skill complementarity with factor inputs. This implies that the impact of a staying low-ability entrepreneur on labor demand and the wage rate is smaller than the impact of an entering high-ability entrepreneur, i.e. $\partial \tilde{w} / \partial n^{L}<\partial \tilde{w} / \partial n^{H}$. In words, two staying low-ability heirs of family firms prevent entry of 
less than two descendants of workers with high ability.

The partial crowding out of high-ability descendants of workers by low-ability owners of family firms incurs a twofold burden on the economy. High-ability entrepreneurs invest more, which has a positive effect on economic performance. Furthermore high-ability entrepreneurs produce more output for any given input combination. These losses of scale and productivity do not necessarily imply the conclusion that a continuation-friendly tax system should be abandoned (for efficiency reasons). The losses have to be compared with the potential gains from saved transaction costs. And, of course, a continuation-friendly tax policy does not automatically imply that a Type 2 equilibrium is assumed since the continuation value $\Delta$ may be still below the threshold.

Finally, note that Corollary 2 and Proposition 2 compare equilibria under the ceteris paribus condition of holding $\tau_{k}$ constant. A clear-cut conclusion on theoretical grounds is thus only possible if the preferential treatment of continued businesses results from a discriminatory tax increase for sold businesses. In this case, $\tau_{s}$ rises at constant $\tau_{k}$ leaving equilibrium wages and employment unaffected. Thus, if a transition from Type 1 to Type 2 equilibrium has been caused by a change of $\tau_{s}$, there will be unambiguously fewer high-ability entrepreneurs. In this case we can furthermore prove the following result concerning aggregate welfare, $\int_{0}^{1} U(i) \mathrm{d} i$.

Proposition 3. Introducing preferential tax treatment of continued businesses $\left(\tau_{s}>\tau_{k}\right)$ by raising tax rate $\tau_{s}$, leaves aggregate welfare in a given type of equilibrium unaffected. If the economy turns from a Type 1 to a Type 2 equilibrium, then a reduction of welfare is more likely to occur if costs of firm dissolution are low (i.e., $q$ is high).

If, however, the preferential treatment has (also) been caused by a tax cut for continued businesses $\tau_{k}$, we may observe possibly counteracting forces to the potentially arising negative crowding-out effect just discussed. This is because a decrease in $\tau_{k}$ affects factor inputs of entrepreneurs (directly and through raising the equilibrium wage rate $w^{*}$ ) and thereby may also change the number of firms in a given type of equilibrium. ${ }^{12}$ The theoretical indeterminacy in this empirically particularly relevant case makes the subsequent quantitative analysis all the more important. We thus continue with a calibration of the model in order to further assess the role of tax schemes and transaction costs on the continuation of family firms and on output, investment, and utility of the individual types of entrepreneurs and workers.

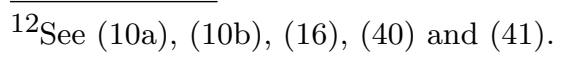




\section{Calibration}

We calibrate the model with German data. The case of Germany appears to be ideal because inheritance law is in the process of reformation and several tax scenarios are currently highly debated among legislature, jurisdiction, business associations, and the general public. According to the old law, real estates and businesses get a preferential treatment vis-à-vis cash, shares, bonds, and other bequests, i.e. $0<\tau_{k}=\tau_{s}<\tau_{b}$. This will be our policy case 1. Recently, however, the Federal Constitutional Court (Bundesverfassungsgericht) has ruled against the preferential treatment of particular kinds of bequests because it does not conform to the principle of equality. This means that the current tax system can only operate until 2009. If there is no tax reform until then, family firms will be treated like other bequests, i.e. $0<\tau_{k}=\tau_{s}=\tau_{b}$, our policy case 2 .

The loophole left by the Constitutional Court is that preferential tax treatment is acceptable if it is justifiably desirable from a general economic viewpoint. Against this background, many see a reform that implements a preferential treatment of continued family firms as the most likely outcome for the future. Such a policy could be justified by the argument that transactions costs are saved through the avoidance of firm dissolution, therewith explaining a general economic interest. Furthermore, a continuation-friendly inheritance tax would implement the recommendations of the European Commission (see introduction). In December 2007 the Bundestag (the lower house of parliament) has launched a reform of the inheritance tax law which yet needs approval by the Bundesrat (the upper house of parliament). It includes an 85 percent exemption on business assets over a period of 10 years, as long as the sum of the salaries paid is at least 70 percent of the original amount and as long as the heir keeps the business for at least 15 years. At the same time, however, depreciation and accounting rules have been tightened. We thus try to approximate the preferential treatment of continued firms, $0<\tau_{k}<\tau_{s}=\tau_{b}$, by setting $\tau_{k}=\tau_{s} / 2$, which constitutes our case 3 .

If the transaction cost argument really holds, it can be (and is indeed) argued in favor of a complete abolishment of taxes on continued firms. According to the original proposal by Chancellor Angela Merkel, for example, inheritance tax payments of family firms could be effectively reduced by 10 percent for every year that the heirs continue the business. As a consequence the tax burden would be cut to zero within a decade, i.e. within less than a generation. No taxes on inherited firms is thus our case $4, \tau_{k}=0, \tau_{s}=\tau_{b}>0$. Finally, for comparison, we 
investigate case 5 according to which all taxes on inherited business are abolished irrespective of their continuation. While this case is probably hypothetical for Germany, it might be relevant elsewhere. Table 1 summarizes the set up of our policy experiment.

Table 1: Investigated Inheritance Tax Policies

\begin{tabular}{llll}
\hline \hline case & policy & implementation & \\
\hline 1 & preferential treatment of family firms & $\tau_{k}=\tau_{b} / 2$ & $\tau_{s}=\tau_{k}$ \\
2 & no preferential treatment & $\tau_{k}=\tau_{b}$ & $\tau_{s}=\tau_{k}$ \\
3 & preferential treatment of continued firms & $\tau_{k}=\tau_{b} / 2$ & $\tau_{s}=\tau_{b}$ \\
4 & no tax on continued firms & $\tau_{k}=0$ & $\tau_{s}=\tau_{b}$ \\
5 & no tax on family firms & $\tau_{k}=0$ & $\tau_{s}=0$ \\
\hline \hline
\end{tabular}

The typical firms that we have in mind when conducting the policy experiments are the small and medium enterprises (SMEs) of the so called German "Mittelstand", which encompasses 99 percent of all German companies and employs about 70 percent of the labor force. ${ }^{13}$ Four percent of the German population lives in entrepreneur households, which would suggest to match $n$ to 0.04 . On the other hand, the average SME owner employs 10 workers, which would suggest that $n$ equals $1 / 11 \approx 0.09$. We solve this dilemma by matching $n=0.07$ (which is the percentage of self-employed households in Germany).

Currently about 30 percent of Germany's family businesses are planning on a succession of the firm within the next years. According to a poll in the manufacturing sector 43 percent of firm owners state that the expected inheritance tax reform will be of "very high" importance for their solution of the succession problem. A further 27 percent state that the tax reform will be of "high" importance. About 30 percent of entrepreneurs are reckoning on solving the succession problem by selling or closing their firm. We thus try to match an exit rate of 0.3 with our calibration. ${ }^{14}$

According to a study by ZEW (2004) the market value of the average German non-corporation is 4.4 million Euros. Under the current law the marginal tax rate on an inheritance of this size (if inherited by a son or daughter) is 19 percent. Yet, inherited family businesses are treated favorably. Besides the possibility to defer tax payment, family firms are also entitled to a $35 \%$ discount of the tax base, and other forms of relief. According to ZEW's calculations the effective

\footnotetext{
${ }^{13}$ For this and the following data on Germany's SME, see Deutsche Bank (2007) and BDI (2006). According to the EU definition, a SME has less than 250 employees and sales revenue not exceeding EUR 50 Mio.

${ }^{14}$ Many European countries (but not the U.S.) show similar characteristics. 99 percent of the European enterprises are SMEs. The average European SME employs 6 people and $66 \%$ of the European labor force are employed in SMEs (but only 33\% of the U.S. labor force). See European Commission (2003) and Deutsche Bank (2007).
} 
average inheritance tax rate on a family firm of average size would be just $3.8 \%$. For the model's calibration we are, however, interested in marginal taxes. We thus set $\tau_{b}=0.19$ and account for the beneficial treatment of firm wealth by setting $\tau_{k}=\tau_{s}=1 / 2 \cdot \tau_{b}$ in our policy case $1 .{ }^{15}$

We calibrate the marginal elasticity of utility from bequests, $\eta$, according to the estimates in Kopczuk and Slemrod (2001). The most applicable of their results is probably the correlation of the reported estates with the estate tax at age 45 of the donor. This allows us to imagine age 45 as the age at which a new generation takes over the family firm and starts planning about bequests. The elasticity of the bequest with respect to 1 minus the tax rate is estimated as 0.16 , implying $(1-\eta) / \eta=0.16$. This leads to the specification of $\eta=0.862$ in our benchmark setup. By sensitivity analysis we take into account that Kopczuk and Slemrod have reported different estimates for alternative specifications, sometimes insignificantly different from zero, and that their study was anyway carried out with data for U.S. households.

The specification of managerial ability and the intergenerational inheritance of managing skills are based as closely as possible on the innovative calibration of these parameters by Caselli and Gennaioli (2006). They show that for a steady-state distribution of ability the probabilities to inherit one's parent ability must fulfil $p^{L}=1-\lambda+\lambda \mu$ and $p^{H}=\lambda+\mu-\lambda \mu$ for a given share of high-ability types in the population $\lambda$ and a given intergenerational correlation of talent $\mu$. Based on the psychological literature about the inheritance of IQ (and hoping that transmission of managerial talent behaves not too differently) they fix $\mu=0.4$. Interestingly this value is not too far away from Galton's (1877) famous $1 / 3$ observed for height and other personal characteristics that are inherited by nature. Casselli and Gennaioli then set $\lambda=0.1$ and use the implied values of $p^{H}$ and $p^{L}$ together with Perez-Gonzales' (2001) estimate that dynastic successions in the U.S. lead to an average decline in the return on assets of 20 percent to come up with the result that $a^{H}=1.33 \cdot a^{L}$ (all parameter names are adjusted to the present paper's notation).

Of course, we cannot adopt all parameter values from their study because we are dealing with a different model. Since Caselli and Gennaioli admit to know relatively little about $\lambda$, the population share of managerially talented people, we take this as our "degree of freedom". We

\footnotetext{
${ }^{15}$ In many European countries there are similar preferential treatments of inherited firm wealth. Interestingly, the ZEW study also computes the hypothetical effective tax rate that would apply for the average German firm in 15 other countries. In the resulting ranking Germany's actual tax is placed just in the middle at number 7 with many Western European countries relatively close by. The most prominent outliers are the U.K. (zero tax rate) and the U.S. (36\%). Note that we take care of less and more favorable tax treatments with our policy cases 2-5.
} 
thus set $\mu=0.4$ and $a^{H}=1.33 \cdot a^{L}$ and take over the two equations determining $p^{L}$ and $p^{H}$ but use $\lambda$ to adjust our model to the empirical exit ratio.

On average the startup of a new business in Germany takes 42 days and costs 15.7 percent of GDP per capita, according to Djankov et al. (2002). In order to relate these numbers to our specification of $\bar{k}$ we have to take into account that Djankov et al.'s figures are based on GDP per capita per year whereas our model economy produces GDP per generation. The length of a generation is best conceptualized as the length of the time period spend by a member of a dynasty of entrepreneurs as head of the business. Imagining that he has inherited the firm from his grandfather when he was 45 years old and will bequest the firm to his son when he is 70 gives an estimate for period length of 25 years. Comparing the monetary start-up costs with our model-GDP per capita at the initial steady-state (which is 3.22 such that the annual GDP per capita equals $3.22 / 25=0.129$ ) we get an estimate of $\bar{k}=0.129 \times 0.157=0.02$. However, we may also want to include time costs taking account of lost opportunities for the non-working firm founder. Djankov et al. estimate total startup costs, including monetary and time cost, as 32.5 percent of GDP per capita. This renders an estimate of $\bar{k}=0.042$. We take this as our benchmark value and conduct sensitivity analysis.

A parameter we know little about is $q$. We try to get around the uncertainty problem by conducting two experiments. Given the numerical specification of the model, it turned out that the equilibrium threshold of Proposition 1 is crossed for a value of $q$ between 0.7 and 0.75 . We first consider the case of 0.75 for which the economy is situated at a Type 1 equilibrium, i.e. given the initial tax policy all firms are led by high-ability entrepreneurs. When $q=0.7$ the benchmark economy is situated at a Type 2 equilibrium where the market is shared by entrepreneurs of high and low ability. Qualitatively, the first scenario captures the notion that transaction costs are relatively low and that Germany's Mittelstand entrepreneurs are of high ability. The notion that high transaction costs in the process of firm dissolution are an important structural problem and that there are also low-ability entrepreneurs present in Germany's economy is captured by the second scenario. Following numerous previous calibration exercises we set the capital share $(1-\alpha)$ to 0.4 .

We fix the remaining three parameters, the value of low-ability skills $a^{L}$, the share of the managerially talented people $\lambda$, and the depreciation rate $\delta$ so that the model matches three statistics: the share of entrepreneurs in the population $(n=0.07)$, the exit rate, i.e. the number 
of exiting entrepreneurs relative to the number of entrepreneurs ( 0.3 as explained above), and the wealth share hold by entrepreneurs. Denote the capital stock employed by high-ability and low-ability entrepreneurs by $k^{H}$ and $k^{L}$, respectively. According to the model, the wealth share is easily be found by comparing total (after tax) wealth of entrepreneurs $\left(n^{H} k^{H}+n^{L} k^{L}\right)(1-$ $\delta)\left(1-\tau_{k}\right)$ and total wealth of workers $(1-n)\left(1-\tau_{b}\right) \bar{b}$. Empirically, however, we were not able to find the appropriate statistics. In the U.S. entrepreneurs hold $40 \%$ of total wealth according to Quadrini (2000). For Germany we know that the self-employed hold $15 \%$ of all wealth (ZEW, 2005). One explanation for the unexpectedly huge cross-country difference is that not all selfemployed are entrepreneurs, certainly not in the spirit of the current model. Another known statistics is that the highest decile of Germany's wealth distribution holds $47 \%$ of total wealth. Perhaps this value fits our model better. Again, we meet the parameter uncertainty by choosing an "intermediate" value of $40 \%$. From benchmark settings we obtain the missing parameters as $a^{L}=2.25, \lambda=0.5$ and $\delta=0.61$. Together with $\mu=0.4, \lambda=0.5$ implies $p^{L}=p^{H}=0.7$.

\section{The Quantitative Impact of Inheritance Tax Reforms}

As explained, we investigate five policy cases for an economy that is initially situated at one of two types of equilibria. For each case and type of equilibrium we evaluate several statistics: the number of firms and the number of high-ability entrepreneurs, the exit rate and entry rate, i.e. the share of descendants of workers who become entrepreneur, income per capita $y$, the aggregate capital labor ratio $k / l$, aggregate TFP, investment rates of entrepreneurs, savings rates of workers, and the utility experienced by the different groups in our model society. Finally we compute aggregate welfare as the weighted sum of utilities where the weights are the population shares of the different groups.

Table 2 summarizes the results when there are only high-ability entrepreneurs initially, i.e. in our policy case 1 . The first column shows the performance of the economy for policy case 1 . The fact that low-ability heirs exit immediately implies the assumption of a relatively high presence of high-ability types in the economy and a relatively high probability to inherit managerial talent. According to Proposition 1, the exit rate equals $1-p^{H}$ in Type 1 equilibrium (matched to 30 percent initially, given a probability to inherit one's parent high managerial skills of $\left.p^{H}=0.7\right)$ and $p^{L} n^{L} / n$ in Type 2 equilibrium. The entry rate is $\left(1-p^{H}\right) n^{H} /\left(1-n^{H}\right)$ in Type 1 and $p^{L} n^{L} /(1-n)$ in Type 2 equilibrium. In policy case 1 about 2.2 percent of descendants 
of workers become entrepreneur. One sees also that the model is able to reflect the empirical regularity found by Gentry and Hubbard (2004) that investment of new entrants (inventer) is much higher than investment of heirs of family firms (invstay). The savings rate of heirs who abandon a family firm $\left(s_{\text {exit }}\right)$ and become worker is relatively low compared to that of workers who are descendant of workers $\left(s_{\text {stayout }}\right)$. To understand this outcome note that in a Type 1 equilibrium low-ability heirs exit immediately. This implies that low-ability heirs of family firms must have inherited the firm from a high-ability parent. High ability parents in turn run large firms, which makes the exiting low-ability heirs much wealthier than workers. They can largely live off their inherited wealth. This fact is also reflected by utilities. Exiting low-ability heirs of family firms experience utility $\left(u_{\text {exit }}\right)$ of a magnitude more closely to that of staying high-ability entrepreneurs $\left(u_{\text {stay }}^{\text {high-high }}\right)$ than to that of descendants of workers $\left(u_{\text {enter }}\right) .{ }^{16}$

Policy case 2 abolishes the preferential tax treatment of inherited businesses (increase in both $\tau_{k}$ and $\tau_{s}$ ). The economy remains in a Type 1 equilibrium implying that the incentive to exit is unchanged. The incentive to enter however gets lower, there are 10 percent less firms in the market and wages are lower, according to (16). Consequently, firms operate a somewhat less capital intensive technology. With less capital but more labor employed output per capita remains almost unchanged. Investment rates are somewhat lower for entering entrepreneurs but much higher for staying entrepreneurs because they have to replace the capital stock lost through increased inheritance tax payments. Workers are benefitting from the reform because the small loss through lower wages is overcompensated by transfers from the redistribution of tax revenue. Utility of workers $\left(u_{\text {enter }}\right)$ is higher than under the initial policy. Workers as the largest group in society are dominating the result, aggregate welfare is higher than in initial equilibrium. The most pronounced effect of the policy is on wealth distribution. The wealth share of entrepreneurs (wealth) is lower by three percentage points.

Policy case 3, the preferential tax treatment of continued firms triggers a structural break. Motivated by tax alleviation low-ability heirs continue the family business unless they have inherited it from a low-ability parent. As a consequence, the market is shared by high and low-ability entrepreneurs. Note that coming from case 1 our case 3 implies an increase of $\tau_{s}$ at constant $\tau_{k}$, i.e. the scenario which has been already covered analytically by Corollary 2 and Proposition 2 and 3. Since the policy change is obviously strong enough to initiate the threshold

\footnotetext{
${ }^{16}$ Recall that descendants of workers who enter the market as entrepreneurs have in equilibrium the same utility as those who stay out.
} 
TABLE 2: Consequences of inheritance tax policy when there are only high-ability entrepreneurs initially (Type 1 equilibrium)

\begin{tabular}{lrrrrr}
\hline \hline & case 1 & case 2 & case 3 & case 4 & case 5 \\
\hline$n$ (in \%) & 7.00 & 6.29 & 8.81 & 9.66 & 7.70 \\
$n^{H}$ (in \%) & 7.00 & 6.29 & 6.78 & 7.43 & 7.70 \\
exit rate (in \%) & 30.00 & 30.00 & 6.92 & 6.92 & 30.00 \\
entry rate (in \%) & 2.26 & 2.01 & 0.67 & 0.74 & 2.50 \\
\hline$y$ & 3.22 & 3.23 & 2.41 & 2.40 & 3.21 \\
$k / l$ & 1.48 & 1.47 & 1.84 & 1.86 & 1.50 \\
TFP & 2.96 & 2.96 & 2.79 & 2.79 & 2.96 \\
wealth (in \%) & 40.00 & 37.10 & 40.31 & 43.05 & 42.70 \\
\hline inv stay (in \%) & 27.77 & 29.15 & 27.77 & 26.37 & 26.37 \\
inv enter (in \%) & 41.14 & 41.02 & 41.14 & 41.26 & 41.26 \\
$s_{\text {exit }}$ (in \%) & 10.70 & 11.03 & 29.29 & 29.72 & 10.43 \\
$s_{\text {stayout (in \%) }}$ & 25.39 & 25.05 & 25.41 & 25.76 & 25.75 \\
\hline$u_{\text {stag }}^{\text {higigh }}$ & 15.36 & 15.38 & 15.32 & 15.34 & 15.34 \\
$u_{\text {high-low }}^{\text {stay }}$ & - & - & 12.99 & 13.08 & - \\
$u_{\text {loway }}$ stagh & - & - & 8.99 & 9.02 & - \\
$u_{\text {exit }}$ & 13.40 & 13.22 & 8.72 & 8.68 & 13.55 \\
$u_{\text {enter }}$ & 9.17 & 9.25 & 9.13 & 9.08 & 9.08 \\
\hline welfare & 9.56 & 9.59 & 9.49 & 9.49 & 9.52 \\
\hline \hline
\end{tabular}

Parameters: $q=0.75, \alpha=0.6, \delta=0.61, \bar{k}=0.042, \eta=0.86$, $a^{L}=2.25, a^{H}=1.33 a^{L}, \mu=0.4, \lambda=0.5, \tau_{b}=0.19$. TFP denotes aggregate productivity, $y$ is income per capita, "wealth" denotes the wealth share of entrepreneurs, inv $v_{x}$ and $s_{x}$ denotes investment and savings rates of group $x, u_{x}$ is utility of group $x$. See text for further explanations.

crossing we know already from formal analysis that we can expect more firms in total, less firms led by high-ability entrepreneurs, and lower aggregate welfare.

Besides low-ability entrepreneurs there occurs a second new species at a Type 2 equilibrium: high-ability heirs of low-ability entrepreneurs. These are the talented grandsons of talented founders and sons of untalented fathers. We observe some crowding out of high-ability entrepreneurs, but the more pronounced effect is the increased total number of firms in the market. We observe also a huge drop of exit and entry rates showing that the continuation-friendly policy is indeed very effective with respect of preventing exit.

Unfortunately, lower exit and entry implies also less creative destruction and entails detrimental effects on output per capita and aggregate TFP. On average, firms are now smaller and employ less workers per unit of capital. Workers lose from the policy change since they receive less transfers from tax revenue. 
The most drastic effect of the policy is that on utility of exiting entrepreneurs $\left(u_{\text {exit }}\right)$, a "third-generation" effect that seems to be completely overlooked in the public debate. Exiting entrepreneurs are now suffering not only from loss through transaction costs but also from the fact that they have inherited their firm from a low-ability parent who was caused to continue the family business inherited from a high-ability grandparent. This makes the inheritance of descendants of low-ability entrepreneurs - and therefore their utility - smaller than that of descendants of workers. The staying high-ability heirs of low-ability fathers continue the business but fare only little better than the exiting ones and worse than entering entrepreneurs (workers) although these have to bear the startup cost. Altogether this outcome strikingly demonstrates the power of a low-ability entrepreneur in driving down business wealth.

One might think that at least one group in society benefits from the saved transaction costs, namely the staying low-ability heirs of high-ability entrepreneurs (e.g. the sons and daughters of the founder of the firm). In case 3 they prefer to stay and experience utility of $u_{\text {stay }}^{\text {high-low }}=12.99$ against exiting and receiving utility of 12.21 (the latter hypothetical outcome is not shown in the Table). Interestingly, however, the general equilibrium analysis reveals that even this group experiences higher utility in case 1 and case 2 when it exits immediately but benefits from the generally more favorable macroeconomic conditions (and experiences utility of 13.40 or 13.22 , respectively). In conclusion, not only is the continuation-friendly policy clearly welfare reducing but also there is not even a single group in society benefiting from it in general equilibrium.

With case 4 we consider the complete abolishment of taxes on continued family firms. Structurally the case is identical to the previous one. The economy assumes again a Type 2 equilibrium. Utility improves only slightly for high-ability heirs of family firms and is still lower for staying low-ability heirs compared to case 1 and 2 where they abandon the family business. Finally, case 5 shows the consequences of abolishing taxes on inherited family businesses irrespective of their continuation. This policy re-establishes the Type 1 equilibrium and leads to an overall increase of firms led by high-ability entrepreneurs through increasing entry. We observe small gains for high-ability entrepreneurs and large gains for exiting heirs of family firms. Workers, the largest group in society, lose somewhat and aggregate welfare remains unchanged. One also sees that the policy improves social mobility; some former workers are attracted to entrepreneurship and the entry rate rises by 0.24 percentage points. As a side-effect this leads to increasing wealth inequality. 
TABLE 3: Consequence Inheritance tax policy when there is mixed ability of entrepreneurs initially (Type 2 equilibrium)

\begin{tabular}{lrrrrr}
\hline \hline & case 1 & case 2 & case 3 & case 4 & case 5 \\
\hline$n$ (in \%) & 7.00 & 6.31 & 7.00 & 7.68 & 7.68 \\
$n^{H}$ (in \%) & 4.55 & 4.10 & 4.55 & 4.99 & 4.99 \\
exit rate (in \%) & 30.00 & 30.00 & 30.00 & 30.00 & 30.00 \\
entry rate (in \%) & 2.26 & 2.02 & 2.26 & 2.49 & 2.49 \\
\hline$y$ & 2.55 & 2.57 & 2.55 & 2.54 & 2.54 \\
$k / l$ & 2.41 & 2.39 & 2.41 & 2.43 & 2.43 \\
TFP & 3.09 & 3.09 & 3.09 & 3.09 & 3.09 \\
wealth (in \%) & 40.00 & 37.18 & 40.00 & 42.62 & 42.62 \\
\hline inv & 29.48 & 30.63 & 29.48 & 28.32 & 28.32 \\
inv enter $_{\text {ent }}$ (in $\left.\%\right)$ & 40.70 & 40.62 & 40.70 & 40.77 & 40.77 \\
$s_{\text {exit }}$ (in \%) & 25.19 & 25.26 & 25.60 & 25.95 & 25.12 \\
$s_{\text {stayout }}$ (in \%) & 22.02 & 21.72 & 22.00 & 22.28 & 22.32 \\
\hline$u_{\text {stay }}^{\text {high-high }}$ & 19.26 & 19.25 & 19.26 & 19.28 & 19.27 \\
$u_{\text {htag }}^{\text {stow }}$ & 16.31 & 16.21 & 16.31 & 16.41 & 16.40 \\
$u_{\text {staw }}^{\text {lowigh }}$ & 9.36 & 9.35 & 9.36 & 9.38 & 9.37 \\
$u_{\text {exit }}$ & 9.15 & 9.14 & 9.10 & 9.06 & 9.16 \\
$u_{\text {enter }}$ & 9.60 & 9.65 & 9.60 & 9.56 & 9.55 \\
\hline welfare & 9.96 & 9.96 & 9.96 & 9.96 & 9.96 \\
\hline \hline
\end{tabular}

Parameters: as in Table 2 except $q=0.7$ which requires recalibration: $\delta=0.67, a^{L}=2.54, \lambda=0.102$ to match the model economy's characteristics.

In Table 3 we turn to the Type 2 scenario by setting $q=0.7$ so that transaction costs become large enough for the first generation of low-ability heirs to keep an inherited firm already for policy case 1, i.e. although the inheritance tax policy is not continuation-friendly. The fact that low-ability entrepreneurs stay implies that we have to recalibrate the three "free parameters" in order to meet the imposed statistics. The strongest effect is here on $\lambda$. For matching an exit rate of 30 percent we have to assume that only 10 percent of the population are endowed with high managerial ability. As consequence, the probability to inherit one's parent high ability $p^{H}$ falls from 0.7 to 0.46 whereas $p^{L}$ rises to 0.94 . We also have to assume that low-ability firms are generally more productive ( $a^{L}$ rises to 2.54 ) implying that we cannot make any quantitative cross-scenario comparisons between Table 2 and Table 3.

Given that the economy is already at a Type 2 equilibrium initially, no tax reform induces a threshold crossing and, consequently, policy effects are comparatively small. Interestingly, the macroeconomic variables assume almost identical values under case 1 and 3 . This suggests that a transition towards a continuation-friendly policy is indeed capable to preserve the status quo 
outcome if the status quo policy has to be abandoned (as requested by the German Constitutional Court). If we can justifiably assume that the economy is situated at a Type 2 equilibrium and preserving the status quo is the policy goal, then the case 3 policy is clearly effective.

The case 4 policy, i.e. the abolishment of all taxes on continued firms improves slightly welfare of heirs of high-ability entrepreneurs at the expense of workers and heirs of low-ability entrepreneurs. Case 5, which abolishes all taxes on family firms, does not lead to any further important changes. The most pronounced effect compared to case 4 is the higher utility of exiting heirs because the tax law does not punish them any longer for not keeping the business. As a consequence they can enjoy more utility from consumption, visible also in the drop of the savings rate of exiting heirs of family firms.

For an intuition of these results, observe that inheritance tax policy has its most pronounced effects through exit decisions if the economy is at a Type 1 equilibrium (Table 2) but operates exclusively through the entry decision at a Type 2 equilibrium (Table 3 ). At a Type 2 equilibrium, a continuation-friendly tax policy affects saving and utility of staying and exiting entrepreneurs but it cannot affect the exit rate, at least not when there is exit according to our assumption A1, i.e. when two low-ability heirs in a row always imply exit. Since the continuation-friendly policy runs through entry of new entrepreneurs, it operates like a general reduction of taxes on family firms. This is clearly visible in Table 3. Entry rises as the tax on family firms decreases irrespective of whether the policy is tied to continuation. Interestingly, at a Type 2 equilibrium a policy intended to be continuation-friendly is indeed continuation-neutral and entry-friendly.

A general observance is that tax reforms have only mild consequences at a Type 2 equilibrium compared to their drastic effects at a Type 1 equilibrium. We therefore focus the following sensitivity analysis on scenarios where there are only high-ability entrepreneurs initially. Given limited space we present only three macro variables, the number of high-ability entrepreneurs, income per capita, and aggregate welfare. The most interesting result so far was that the continuation-friendly policy failed completely: It has reduced aggregate welfare and the targeted persons, i.e. entrepreneurs who exit in case 1 and 2 but are made to continue the business under case 3 and 4, have been actually made worse off. In order to verify the robustness of this result we also report utility of members of this group, the low-ability heirs of high-ability entrepreneurs, denoted by $u^{\text {high-low }}$. These persons remain entrepreneurs in Type 2 equilibrium $\left(u^{\text {high-low }}=u_{\text {stay }}^{\text {high-low }}\right)$ and become workers in Type 1 equilibrium $\left(u^{\text {high-low }}=u_{\text {exit }}\right)$. For 
better comparison Table 4 begins with reiterating the values of these four variables for the benchmark calibration.

TABLE 4: Sensitivity analysis

\begin{tabular}{|c|c|c|c|c|c|c|c|}
\hline & & case 1 & case 2 & case 3 & case 4 & case 5 & explanation \\
\hline \multirow[t]{4}{*}{ Benchmark } & $n^{H}($ in $\%)$ & 7.00 & 6.29 & 6.78 & 7.43 & 7.70 & specification as \\
\hline & $y$ & 3.22 & 3.23 & 2.41 & 2.40 & 3.21 & in Table 2 \\
\hline & $u^{\text {high-low }}$ & 13.40 & 13.22 & 12.99 & 13.08 & 13.55 & \\
\hline & welfare & 9.55 & 9.59 & 9.49 & 9.49 & 9.52 & \\
\hline \multirow[t]{4}{*}{$\bar{k}=0.1$} & $n^{H}($ in $\%)$ & 7.00 & 6.29 & 6.77 & 7.43 & 7.70 & high entry costs \\
\hline & $y$ & 3.13 & 3.14 & 2.34 & 2.33 & 3.12 & \\
\hline & $u^{\text {high-low }}$ & 13.34 & 13.15 & 13.01 & 13.11 & 13.49 & \\
\hline & welfare & 9.50 & 9.53 & 9.44 & 9.44 & 9.46 & \\
\hline \multirow[t]{4}{*}{$\eta=0.99$} & $n^{H}$ (in \%) & 7.00 & 6.30 & 6.77 & 7.41 & 7.69 & no effect of tax \\
\hline & $y$ & 3.31 & 3.32 & 2.47 & 2.46 & 3.30 & on size of bequest \\
\hline & $u^{\text {high-low }}$ & 106.37 & 106.19 & 105.99 & 106.08 & 106.52 & \\
\hline & welfare & 102.40 & 102.44 & 102.34 & 102.34 & 102.37 & \\
\hline \multirow[t]{4}{*}{$\eta=0.6$} & $n^{H}$ (in \%) & 7.00 & 6.26 & 6.79 & 7.49 & 7.74 & high effect of tax \\
\hline & $y$ & 2.75 & 2.75 & 2.06 & 2.05 & 2.75 & on size of bequest \\
\hline & $u^{\text {high-low }}$ & 7.82 & 7.63 & 7.52 & 7.62 & 7.98 & \\
\hline & welfare & 4.37 & 4.38 & 4.31 & 4.31 & 4.33 & \\
\hline \multirow[t]{4}{*}{$\mu=0$} & $n^{H}($ in $\%)$ & 7.00 & 6.29 & 6.64 & 7.26 & 7.70 & no intergen. \\
\hline & $y$ & 3.22 & 3.23 & 2.06 & 2.04 & 3.21 & correlation of IQ \\
\hline & $u^{\text {high-low }}$ & 13.43 & 13.27 & 12.99 & 13.09 & 13.55 & i.e. exit rate $=50$ \\
\hline & welfare & 9.55 & 9.61 & 9.45 & 9.45 & 9.49 & \\
\hline \multirow[t]{4}{*}{$\mu=0.8$} & $n^{H}($ in $\%)$ & 7.00 & 6.29 & 6.92 & 7.61 & 7.70 & high intergen. \\
\hline & $y$ & 3.22 & 3.23 & 2.90 & 2.89 & 3.21 & correlation of IQ \\
\hline & $u^{\text {high-low }}$ & 13.37 & 13.16 & 12.99 & 13.08 & 13.55 & i.e. exit rate $=10$ \\
\hline & welfare & 9.56 & 9.57 & 9.54 & 9.54 & 9.55 & \\
\hline \multirow[t]{4}{*}{$a^{H} / a^{L}=1.6$} & $n^{H}($ in $\%)$ & 7.00 & 6.29 & 6.82 & 7.48 & 7.70 & higher ability \\
\hline & $y$ & 3.22 & 3.23 & 2.42 & 2.41 & 3.21 & differential \\
\hline & $u^{\text {high-low }}$ & 13.40 & 13.22 & 12.74 & 12.83 & 13.55 & \\
\hline & welfare & 9.55 & 9.59 & 9.49 & 9.49 & 9.52 & \\
\hline \multirow[t]{4}{*}{$\tau_{b}=0.35$} & $n^{H}$ (in $\left.\%\right)$ & 7.00 & 5.57 & 6.78 & 8.09 & 8.41 & higher \\
\hline & $y$ & 3.11 & 3.13 & 2.32 & 2.30 & 3.09 & initial tax \\
\hline & $u^{h i g h-l o w}$ & 12.04 & 11.67 & 11.38 & 11.56 & 12.26 & \\
\hline & welfare & 9.20 & 9.26 & 9.10 & 9.10 & 9.13 & \\
\hline
\end{tabular}

We first consider robustness against substantially higher entry costs, $\bar{k}=0.1$, implying startup costs of more than 70 percent of annual GDP. The incentive for descendants to enter entrepreneurship declines implying lower equilibrium wages and lower income per capita. As a consequence staying low-ability entrepreneurs lose relatively less if the tax system causes them to keep an inherited business (case 3). Yet they would still be better off by exiting and be- 
coming workers (as under case 1,2 and 5). As before, aggregate welfare is lowest under a continuation-friendly tax policy (cases 3 and 4 ).

Next we discuss the effect of varying the marginal elasticity of utility from bequests. For $\eta=0.99 \approx 1$ income and substitution effects approximately balance each other. This closes the bequest channel and all effects operate through exit and entry. Structurally results remain very similar to the benchmark case indicating, once more, that exit and entry are the dominating effect of policy reforms in Type 1 equilibria. For $\eta=0.6$ we observe similar results.

We next consider alternative assumptions about the intergenerational correlation of managing ability, $\mu$. If we would recalibrate the model to match the statistics there would no change of policy effects at all because $\lambda$ would adjust. In order to provoke an effect we fix $\lambda$ at its original value $(\lambda=0.5)$ implying that the model now predicts higher exit rates for lower $\mu$ and lower exit rates for higher $\mu$. We consider the limiting case without any inheritance of managing ability $(\mu=0)$ and a very high intergenerational correlation of ability $(\mu=0.8)$. In both cases there are no surprises. Structurally, the core variables react to tax reforms as for the benchmark calibration.

Furthermore, we consider a higher differential between high and low-ability entrepreneurs. For the model to match the statistics we have to recalibrate $a^{L}=1.87$, i.e. low-ability entrepreneurs are less talented. Because $a^{H}$ is kept at its benchmark level, there are no changes of policy effects if there are only high-ability entrepreneurs. If there are low-ability entrepreneurs, the most pronounced effect is the high utility loss experienced by low-ability heirs when the policy causes them to continue the family firm (cases 3 and 4 ).

Finally we consider a significantly higher tax on inheritances other than family firms $\left(\tau_{b}\right.$ is raised from 0.19 to 0.35 ). While, of course, aggregate welfare is decreasing in the degree of distortionary taxation, results remain structurally identical to the benchmark case.

Summarizing, aggregate welfare under the continuation-friendly policy 3 is never higher than under the non-preferential policy 2. Welfare remains unchanged if the continuation-friendly policy is ineffective with respect to continuation, i.e. when it does not manage to motivate heirs of family firms to keep the business. If it is effective, welfare is lower than under the unconditionally firm-friendly policy 1 and under the non-preferential tax policy 2 in all numerical specifications of the model investigated. In other words, the positive transaction-cost effect from firm continuation never dominates the negative creative-destruction effect. 
Income per capita is always lowest under the continuation-friendly policy and low-ability heirs that are made to continue a family firm always lose vis-à-vis any other policy. Moreover, there is a negative "third generation" effect indicating substantial welfare losses for heirs of low-ability entrepreneurs who were caused to continue a family business by tax allowances. From that we cannot conclude that taxes on family firms should be generally high. Aggregate income is second highest and utility of all types of entrepreneurs and of the heirs is highest for case 5, i.e. when there are unconditionally no taxes on family firms. However, workers who are descendants of workers are the losers in this scenario. Perhaps, their children or grandchildren will benefit through the increasing upward mobility created by the entry-friendly no-tax policy.

\section{Growth Effects}

Finally we consider the dynamic forces of creative destruction and extend the model to allow for productivity growth. Growth is endogenous in the sense that it depends on the fraction of high-ability entrepreneurs in the population, $n^{H}$. The assumption that high-ability entrepreneurs are extraordinarily innovative and exert positive spill-over effects among entrepreneurs finds support in a recent paper by van Praag and Versloot (2007). There, the authors provide a meta-study on the contribution of entrepreneurs (young firms with less than 100 employees) on aggregate productivity growth and conclude that entrepreneurial firms "engender relatively much employment creation, productivity growth and produce and commercialize high quality innovations" (p. 1).

In order to take these results into account we modify the production function slightly. Output of the firm of entrepreneur $i$ at time $t$ is now given by

$$
y_{t}(i)=a_{t}(i)\left(A_{t} l_{t}(i)\right)^{\alpha} k_{t}(i)^{1-\alpha}
$$

where $A_{t}$ measures aggregate productivity. $A_{0}>0$ is given. Increasing productivity over time reflects labor-saving technological progress. We assume that productivity growth is positively influenced by the share of highly able entrepreneurs in the economy.

$$
\frac{A_{t}-A_{t-1}}{A_{t}}=h\left(n_{t}^{H}\right)
$$

where $h^{\prime}(\cdot)>0$.

The basic model is modified further in two ways. First, in order to capture that startup costs 
grow along with the stage of economic development, we calculate them as $\kappa_{t}=\bar{k} A_{t}$. Second, we assume that utility is derived from levels of consumption and net bequest adjusted for productivity. This modelling expresses the idea that individuals have high aspirations when the general degree of economic development is high. ${ }^{17}$ Formally, let $\hat{z}=z / A$ denote the productivityadjusted level of a variable $z$ and modify the utility function (1) to

$$
U_{t}(i)=\hat{c}_{t}(i)+v\left(\hat{b}_{t}^{n e t}(i)\right) .
$$

With these extensions and modifications of the basic model we obtain that $\hat{k}_{t}(i)=\tilde{k}\left(a_{t}(i), \hat{w}_{t}, \tau_{k}\right)$, $\hat{l}_{t}(i)=\tilde{l}\left(a_{t}(i), \hat{w}_{t}, \tau_{k}\right)$ and $\hat{b}_{t}(i)=\bar{b}\left(\tau_{b}\right)$, where the functions $\tilde{k}, \tilde{l}$ and $\bar{b}$ have been defined in Section 3. Consequently, all results of Sections 3 and 4 remain virtually unchanged. (Formally, we just need to replace $w$ by $\hat{w}$ in equations (17)-(41).) At a steady-state, the wage rate $\left(w^{*}\right)$, capital inputs, bequests, consumption and output all grow at the same rate, $h\left(n^{H}\right)$. Consequently, we can prove the following result.

Proposition 4. Introducing preferential tax treatment of continued businesses $\left(\tau_{s}>\tau_{k}\right)$ by raising tax rate $\tau_{s}$ reduces economic growth if the economy turns from Type 1 to Type 2 equilibrium.

The result immediately follows from the fact that a change from Type 1 to Type 2 equilibrium reduces the number of high-ability entrepreneurs (Proposition 2). Again, the situation is less easily assessed if the preferential treatment is also caused by a tax cut for continued firms because negative crowding-out effects possibly counteract with positive, entry provoking effects through increasing net returns on capital. Inspecting our results from Table 2 we see that the expansive effect in fact dominates for the drastic reform case 4 that abolishes taxes on continued firms entirely. For our policy case 3 and - as established analytically - any other reform that unilaterally raises taxes on sold businesses such that a threshold crossing of equilibria occurs results are always unambiguous. The crowding out of highly ably entrants by less able heirs reduces growth.

\section{Conclusion}

In this paper we have analyzed the consequences of inheritance tax reforms on the career decision of individuals and on the aggregate performance of economies. We have argued that

\footnotetext{
17 There is a voluminous literature which supports this notion. See e.g. Grossmann (2001, ch. 2) for a survey. Technically, the assumption leads to simple steady-state expressions for the model's core variables.
} 
the transaction-cost channel, which is mostly emphasized in the public debate, interacts with a creative-destruction channel. This way, the continuation of family firms does not only save agency- and start-up costs through less firm dissolution and less setup of new ones, it may also lead to less entry into entrepreneurship by highly able descendants of workers. Within a general equilibrium model we have shown analytically that there are two types of equilibria - one where firms are exclusively led by highly able entrepreneurs and one where the market is shared by entrepreneurs of high and low ability - and that the design of inheritance taxes has the power to influence the type of equilibrium that an economy assumes.

Using a numerical implementation of the model we have quantitatively investigated the consequences of some currently discussed tax reforms. In a nutshell, we have found that the preferential treatment of continued family firms is either ineffective or disastrous depending on whether it causes a threshold crossing of general equilibrium.

If the preferential tax is ineffective it does neither change aggregate welfare nor the rate of exiting entrepreneurs. It improves slightly welfare of staying entrepreneurs of both high and low ability at the expense of a slight welfare deterioration of both workers and exiting heirs of low-ability entrepreneurs.

If the preferential tax is disastrous, it impedes entry and leads to a qualitative change of equilibria that entails a reduction of aggregate welfare as well as of welfare of the targeted group, i.e., the heirs of family firms that are caused to keep an inherited business. While also workers suffer slightly from deteriorating macroeconomic performance, the most dramatic consequence of the reform is a "third-generation" effect which seems to be completely overlooked in the current debate. Welfare of the exiting sons and daughters of low-ability entrepreneurs is cut down by almost 40 percent irrespective of whether they are themselves of high ability and rebuilt the family firm or of low ability and exit into wage work. If low-ability entrepreneurs continue the business and run down family wealth by investing too little (which is the optimal choice given their low entrepreneurial skills), they make their heirs worse off than the descendants of workers.

Given that our sensitivity analysis has confirmed these results to be robust against parameter variations, we feel save to conclude that our theory does not support preferential tax treatment of continued firms as, for example, suggested by the European Commission and as currently implemented or debated in many countries. Having said this, some qualifications regarding the magnitude of effects are in order. So far, we only managed to derive our results under some 
simplifying assumptions. Most notably, the empirical distribution of entrepreneurial ability is certainly not bivariate but continuous. However, as long as there are heirs of superior and inferior management skills and as long as a continuation-friendly policy causes some less talented heirs to continue a business, the general mechanism developed in this paper is still at work. Secondly, a more general utility function would make inheritances path-dependent. If a lucky dynasty experiences several generations of highly able entrepreneurs in a row it may amass disproportionately big fortunes and additional wealth effects occur that are currently ignored. These distributional consequences may be of second order for our theory, however, which is based solely on efficiency arguments. Anyway, given the empirical evidence mentioned in the introduction regarding the performance of entrepreneurs of second and third generation, several lucky draws in a row seem to be more exception than rule.

In order to limit the length of this paper we have not discussed the possibility that untalented heirs transfer control to hired talented managers. This discussion is available in a separate Appendix. There we show that allowing for external management leaves our theoretical results unaffected. In quantitative analysis we show that also our main results on aggregate income and welfare remain intact. In particular we still find that a tax policy that motivates lowability heirs to continue a family business (with help of external management) lowers aggregate welfare. Intuitively, in an equilibrium with entry and exit it cannot be that external management is available simultaneously at the same cost as ordinary workers and at the same quality as high-ability entrepreneurs (firm-founders). This fact explains why indeed so many SME's are managed by family members. It also implies that, although low-ability heirs are (unsurprisingly) better off with external management, they nevertheless continue to crowd out firm foundation of high-ability descendants of workers. In others words, the creative destruction channel is still dominating welfare consequences. ${ }^{18}$

Nevertheless, instead of claiming that the proposed theory should be the last word on the theoretical and empirical investigation of tax induced firm-continuation, we view it as a first step into this new field. Extensions getting rid of the simplifications mentioned above are interesting (yet challenging) tasks for future research. Other interesting further developments could result from the introduction of psychological and sociological elements, for example amenities (ego-

\footnotetext{
$\overline{18}$ In Germany's manufacturing sector about 85 percent of all firms are family owned and managed. Of these, 90 percent are 100 percent family-owned (BDI, 2006). The Appendix can be downloaded from http://kaldor.vwl. uni-hannover.de/holger/research/papers.php.
} 
rents) from "being entrepreneur", the intergenerational transmission of family values, and peer pressure (from the parent generation) to carry on the business. 


\section{APPENDIX}

Proof of Proposition 1. First, suppose $\Delta<\hat{\Delta}$, which is equivalent to

$$
g\left(a^{L}, w^{*}, \tau_{k}\right)+\Delta(1-\delta) \tilde{k}\left(a^{H}, w^{*}, \tau_{k}\right)<w^{*}+B\left(\tau_{b}\right) .
$$

In this case, in steady state (i.e., $w_{t}=w_{t-1}=w^{*}$ as given by (16)) it is attractive for low-ability descendants of entrepreneurs to exit even if the parent had high ability, according to (14). Thus, all low-ability descendants of entrepreneurs exit, such that $n^{L}=0$. This implies $\tilde{w}\left(0, n^{H}, \tau_{k}\right)=$ $w^{*}$ in long-run equilibrium. Moreover, as the probability of a high-ability entrepreneur to obtain low ability is $1-p^{H}$, the number of exiting firms is $\left(1-p^{H}\right) n^{H}$. Second, suppose $\Delta>\hat{\Delta}$, which is equivalent to

$$
g\left(a^{L}, w^{*}, \tau_{k}\right)+\Delta(1-\delta) \tilde{k}\left(a^{H}, w^{*}, \tau_{k}\right)>w^{*}+B\left(\tau_{b}\right) .
$$

In this case, low-ability descendants of entrepreneurs remain in the market if their parent had high ability. According to assumption A1, they exit if their parent had low ability. Thus, $p^{L} n^{L}$ firms exit, as $p^{L}$ is the share of low-ability entrepreneurs with low-ability offspring. On the other hand the probability that a high-ability entrepreneur has a low ability offspring who continues the family business is $1-p^{H}$. This implies $n^{L}=\left(1-p^{H}\right) n^{H}$ which together with $\tilde{w}\left(n^{L}, n^{H}, \tau_{k}\right)=w^{*}$ implicitly defines the number of high-ability entrepreneurs in equilibrium.

Proof of Corollary 1. First, note that $\lim _{w \rightarrow \underline{w}} g\left(a, w, \tau_{k}\right) \rightarrow \infty$. As $g\left(a, w, \tau_{k}\right)$ is strictly decreasing in $w$ and the right-hand side of (15) is strictly increasing in $w$ without bound, there exists a unique $w^{*}>0$ as given by (16). One can also show that $\lim _{w \rightarrow \underline{w}} \tilde{l}\left(a, w, \tau_{k}\right) \rightarrow \infty$ and $\lim _{w \rightarrow \infty} \tilde{l}\left(a, w, \tau_{k}\right)=0$. Using (17), this implies that both $\tilde{w}\left(0, n, \tau_{k}\right)$ and $\tilde{w}\left((1-\lambda) n, n, \tau_{k}\right)$ are increasing as function of $n$ without bound. Observing Proposition 1 confirms the result.

Proof of Corollary 2. Introducing preferential tax treatment of continued businesses $\left(\tau_{k}<\right.$ $\tau_{s}$ ) by raising $\tau_{s}$ implies that the continuation value per unit of capital, $\Delta$, rises whereas threshold value $\hat{\Delta}$ remains unchanged, according to (18). Applying Proposition 1 confirms the result.

Proof of Proposition 2. For the Type 1 equilibrium, (40) follows from (17) and $n^{L}=0$ (recall part (i) of Proposition 1), where $w^{*}$ is given by (16). In Type 2 equilibrium, (17) and $n^{L}=\left(1-p^{H}\right) n^{H}$ (recall part (ii) of Proposition 1) imply $\left(1-p^{H}\right) n^{H}\left[\tilde{l}\left(a^{L}, w, \tau_{k}\right)+1\right]+$ $n^{H}\left[\tilde{l}\left(a^{H}, w, \tau_{k}\right)+1\right]=1$, which leads to (41). From (40) and (41) we find $\hat{n}^{H 1}>\hat{n}^{H 2}$. Moreover, in type 2 equilibrium, where $n^{L}=\left(1-p^{H}\right) \hat{n}^{H 2}$, the total number of firms is given by $\left(2-p^{H}\right) \hat{n}^{H 2}$. It is easy to show that $\left(2-p^{H}\right) \hat{n}^{H 2}>\hat{n}^{H 1}$ if and only if $\tilde{l}\left(a^{H}, w^{*}, \tau_{k}\right)>\tilde{l}\left(a^{L}, w^{*}, \tau_{k}\right)$, which holds according to (10b). This concludes the proof.

Proof of Proposition 3. Denote utility of a high-ability heir of a high-ability entrepreneur (staying in the market in both types of equilibria) by $u_{\text {stay }}^{\text {high }}$ high and utility of workers (which in equilibrium equals utility of high-ability heirs of workers who become entrepreneurs) by $u_{\text {enter }}$. Moreover, recall that $B$ is the net utility received from making a bequest as a worker $\left(v\left(b^{\text {net }}\right)-b\right)$, and $g\left(a, w, \tau_{k}\right)$ is the sum of the profit of an entrepreneur with ability $a$ and net utility from 
passing on the firm $\left(v\left(b^{\text {net }}\right)-k\right)$. Taking into account the amount of bequests received as well as transfers, in view of utility function (1), we find that in a steady state

$$
\begin{gathered}
u_{\text {stay }}^{\text {high-high }}=g\left(a^{H}, w^{*}, \tau_{k}\right)+\left(1-\tau_{k}\right)(1-\delta) \tilde{k}\left(a^{H}, w^{*}, \tau_{k}\right)+T, \\
u_{\text {enter }}=w^{*}+\left(1-\tau_{b}\right) \bar{b}\left(\tau_{b}\right)+B\left(\tau_{b}\right)+T .
\end{gathered}
$$

Those low-ability descendants of an entrepreneur with ability $a \in\left\{a^{L}, a^{H}\right\}$ who exit the market derive utility

$$
u_{e x i t}(a)=w^{*}+\left(q-\tau_{s}\right)(1-\delta) \tilde{k}\left(a, w^{*}, \tau_{k}\right)+B\left(\tau_{b}\right)+T .
$$

Denote the aggregate welfare level, $\int_{0}^{1} U(i) d i$, in Type 1 and Type 2 equilibrium by $W_{1}$ and $W_{2}$, respectively. We start by deriving $W_{1}$. In Type 1 equilibrium, there are $p^{H} \hat{n}^{H 1}$ and $\left(1-p^{H}\right) \hat{n}^{H 1}$ high-ability and low-ability descendants of (high-ability) entrepreneurs, respectively. Thus,

$$
W_{1}=p^{H} \hat{n}^{H 1} u_{\text {stay }}^{\text {high-high }}+\left(1-p^{H}\right) \hat{n}^{H 1} u_{\text {exit }}\left(a^{H}\right)+\left(1-\hat{n}^{H 1}\right) u_{\text {enter }} .
$$

Substituting expressions (26)-(28) into (29), observing that tax revenue (per capita) equals transfer $T$, using from (16) that $g\left(a^{H}, w^{*}, \tau_{k}\right)=w^{*}+B\left(\tau_{b}\right)+\bar{k}$, and rearranging terms gives us

$$
\begin{aligned}
W_{1}= & w^{*}+B\left(\tau_{b}\right)+p^{H} \hat{n}^{H 1} \bar{k}+\left(1-\hat{n}^{H 1}\right) \bar{b}\left(\tau_{b}\right)+ \\
& (1-\delta) \tilde{k}\left(a^{H}, w^{*}, \tau_{k}\right)\left[p^{H}+q\left(1-p^{H}\right)\right] \hat{n}^{H 1} .
\end{aligned}
$$

In Type 2 equilibrium, there are $p^{H} \hat{n}^{H 2}$ and $\left(1-p^{H}\right) \hat{n}^{H 2}$ high-ability and low-ability descendants of high-ability entrepreneurs, respectively. Both groups stay in the market. Their respective utility levels are $u_{\text {stay }}^{\text {high-high }}$ as given in (26) and

$$
u_{\text {stay }}^{\text {high-low }}=g\left(a^{L}, w^{*}, \tau_{k}\right)+\left(1-\tau_{k}\right)(1-\delta) \tilde{k}\left(a^{H}, w^{*}, \tau_{k}\right)+T .
$$

Moreover, there are $p^{L} n^{L}$ and $\left(1-p^{L}\right) n^{L}$ low-ability and high-ability individuals who inherit a firm from a low-ability entrepreneur, respectively. Their respective utility levels are $u_{\text {exit }}\left(a^{L}\right)$ and

$$
u_{\text {stay }}^{\text {lowigh }}=g\left(a^{H}, w^{*}, \tau_{k}\right)+\left(1-\tau_{k}\right)(1-\delta) \tilde{k}\left(a^{L}, w^{*}, \tau_{k}\right)+T .
$$

Noting that $n^{L}=\left(1-p^{H}\right) n^{H}$ in steady state, we find that

$$
\begin{aligned}
W_{2}= & p^{H} \hat{n}^{H 2} u_{\text {stay }}^{\text {high-high }}+\left(1-p^{H}\right) \hat{n}^{H 2} u_{\text {stay }}^{\text {high-low }}+p^{L}\left(1-p^{H}\right) \hat{n}^{H 2} u_{\text {exit }}\left(a^{L}\right)+ \\
& \left(1-p^{L}\right)\left(1-p^{H}\right) \hat{n}^{H 2} u_{\text {stay }}^{\text {low-high }}+\left[1-\left(2-p^{H}\right) \hat{n}^{H 2}\right] u_{\text {enter }} .
\end{aligned}
$$

Analogously to the derivation of (30), this can be rewritten as

$$
\begin{aligned}
W_{2}= & \left(1-\left(1-p^{H}\right) \hat{n}^{H 2}\right)\left[w^{*}+B\left(\tau_{b}\right)\right]+(1-\delta) \tilde{k}\left(a^{H}, w^{*}, \tau_{k}\right) \hat{n}^{H 2}+ \\
& (1-\delta) \tilde{k}\left(a^{L}, w^{*}, \tau_{k}\right)\left(1-p^{H}\right)\left(1-p^{L}+q p^{L}\right) \hat{n}^{H 2}+\left(1-p^{H}\right) \hat{n}^{H 2} g\left(a^{L}, w^{*}, \tau_{k}\right)+ \\
& {\left[p^{H}+\left(1-p^{L}\right)\left(1-p^{H}\right)\right] \hat{n}^{H 2} \bar{k}+\left[1-\left(2-p^{H}\right) \hat{n}^{H 2}\right] \bar{b}\left(\tau_{b}\right) . }
\end{aligned}
$$

Note that neither $W_{1}$ nor $W_{2}$ depends on $\tau_{s}$, which confirms the first part of Proposition 3 . To decide in which type of equilibrium welfare is higher (for given tax rates), use (30) and (34) to find that $W_{1}<W_{2}$ if and only if

$$
\left(1-p^{H}\right) \hat{n}^{H 2}\left[w^{*}+B\left(\tau_{b}\right)-g\left(a^{L}, w^{*}, \tau_{k}\right)\right]+\left[\left(2-p^{H}\right) \hat{n}^{H 2}-\hat{n}^{H 1}\right] \bar{b}\left(\tau_{b}\right)+
$$




$$
\begin{aligned}
& \left(1-p^{H}\right)(1-\delta)\left[\hat{n}^{H 1} \tilde{k}\left(a^{H}, w^{*}, \tau_{k}\right)-p^{L} \hat{n}^{H 2} \tilde{k}\left(a^{L}, w^{*}, \tau_{k}\right)\right] q \\
< & \left(\hat{n}^{H 2}-p^{H} \hat{n}^{H 1}\right)(1-\delta) \tilde{k}\left(a^{H}, w^{*}, \tau_{k}\right)+\left(1-p^{H}\right)\left(1-p^{L}\right)(1-\delta) \tilde{k}\left(a^{L}, w^{*}, \tau_{k}\right)+ \\
& {\left[\hat{n}^{H 2}-p^{H} \hat{n}^{H 1}+p^{L}\left(1-p^{H}\right) \hat{n}^{H 2}\right] \bar{k} . }
\end{aligned}
$$

Note from assumption Proposition 2 that $\hat{n}^{H 1}>\hat{n}^{H 2}$. Thus, if $q$ rises, the left-hand side is increasing and the right-hand side is unaffected. This concludes the proof.

Talented External Managers. Here we extend our model by allowing low-ability heirs of family businesses to hire talented managers. First we show that our main theoretical results remain qualitatively unaffected. In the numerical part we show for the calibration with German data that external management occurs only for a narrow set of parameters. We finally show that our main result from quantitative analysis continues to hold if there is external management, namely that a policy change towards beneficial treatment of family businesses contingent on their continuation leads to a welfare loss if it motivates low-ability heirs to continue the family firm (with help of external managers). One result of the basic model, however, has to be modified: If high manager quality is available at no or little extra cost (compared to other employees), utility of low-ability heirs may increase if beneficial tax treatment motivates them to keep the firm.

We assume that if a heir hires a high-ability manager his or her firm obtains productivity $a^{M} \in\left(a^{L}, a^{H}\right]$. Thus the firm is as most as productive as an otherwise identical one led by a high-ability entrepreneur. Since we are not building our argument on principal agent mechanisms or imperfect contracting, there must not be any monitoring. Without managing and monitoring obligations, the heir is assumed to supply his labor endowment fulltime for wage work. This is the most drastic assumption that could potentially destroy our results from the basic model. It is straightforward to see that per capita GDP and wages would be lower under the (possibly more realistic) assumption that low-ability heirs were spending all or part of their time on leisure activities thereby living off their externally managed firm.

In order to be capable of their job, managers have to incur a cost $e \geq 0$. This cost comprises the effort of learning firm specific knowledge (which is available at no cost for founder and heirs of the businesses). In equilibrium, high-ability individuals are thus indifferent between being a worker or manager if the wage for managers $w_{t}^{M}$ fulfills $w_{t}=w_{t}^{M}-e$. In other words, $e$ is a wage premium granted for managing tasks, $w_{t}^{M}=w_{t}+e$.

With entry there is still the option for high-ability descendants of worker to establish a new business. In an equilibrium with entry and exit of firms the wage $w^{*}$ is thus still pinned down by condition (16) in the main text, which requires that high-ability types are indifferent between being entrepreneur and worker.

Facing wages $w^{*}$ and thus manager salaries $w^{M}=w^{*}+e$, low-ability heirs who continue a family business hire a manager if $g\left(a^{M}, w^{*}, \tau_{k}\right)-\left(w^{*}+e\right)>g\left(a^{L}, w^{*}, \tau_{k}\right)$. This means that they hire a manager if

$$
e<\hat{e} \equiv g\left(a^{M}, w^{*}, \tau_{k}\right)-g\left(a^{L}, w^{*}, \tau_{k}\right)-w^{*} .
$$

Otherwise, for $e>\hat{e}$, managers are too expensive and are not hired, and the model collapses to 
the model of the main text. Note that the right hand side of (36) may be negative even in the case of $e=0$. In that case, even without any manager premium no managers are hired.

Consider the case where (36) is indeed fulfilled and it pays off to hire managers. In that case all low-ability heirs of high-ability entrepreneurs hire managers. In order to allow for an equilibrium with entry and exit, condition (A1) has to be modified. For exit of firms to exist it is required that

$$
g\left(a^{M}, w^{*}, \tau_{k}\right)+\Delta(1-\delta) \tilde{k}\left(a^{M}, w^{*}, \tau_{k}\right)-e<w^{*}+B\left(\tau_{b}\right) .
$$

Note from (A2) that either $e>0$ or $a^{M}<a^{H}$ must hold. Otherwise, there would never be exit. Family firms would be continued forever no matter how long an uninterrupted series of low-ability forefathers gets. In equilibrium this would also imply that there is no entry, i.e. no upward mobility of high-ability descendants of workers.

Next consider our main result, the threshold between Type 1- and Type 2-equilibrium.

Proposition A.1. Given the possibility of external management (i.e. $e<\hat{e}$ ), there is a threshold value

$$
\hat{\hat{\Delta}} \equiv \frac{w^{*}+e+B\left(\tau_{b}\right)-g\left(a^{M}, w^{*}, \tau_{k}\right)}{(1-\delta) \tilde{k}\left(a^{H}, w^{*}, \tau_{k}\right)}
$$

such that in long-run equilibrium the following holds:

(i) For $\Delta<\hat{\hat{\Delta}}$, there are only high-ability entrepreneurs in the market (i.e., $n^{L}=0$ ). The number of firms, $n=n^{H}$, is given by $\tilde{w}\left(0, n^{H}, \tau_{k}\right)=w^{*}$, with $w^{*}$ as defined by (16). In each period, all firm-heirs who have drawn a low ability, i.e., $\left(1-p^{H}\right) \cdot n^{H}$ firms, exit. (Type 1 equilibrium.)

(ii) For $\Delta>\hat{\hat{\Delta}}$, there are $n^{L}=\left(1-p^{H}\right) \cdot n^{H}>0$ firms led by low-ability entrepreneurs in the market and the number of high-ability entrepreneurs, $n^{H}$, is given by $\tilde{w}\left(\left(1-p^{H}\right) \cdot n^{H}, n^{H}, \tau_{k}\right)=$ $w^{*}$. All low-ability entrepreneurs hire external managers. In each period, all firms owned by low-ability heirs of low-ability parents, i.e., $p^{L} \cdot n^{L}$ firms, exit. (Type 2 equilibrium.)

Proof. First, suppose $\Delta<\hat{\hat{\Delta}}$, which is equivalent to

$$
g\left(a^{M}, w^{*}, \tau_{k}\right)+\Delta(1-\delta) \tilde{k}\left(a^{H}, w^{*}, \tau_{k}\right)-\left(w^{*}+e\right)+w^{*}<w^{*}+B\left(\tau_{b}\right) .
$$

In this case, in steady state (i.e., $w_{t}=w_{t-1}=w^{*}$ as given by (16)) it is attractive for lowability descendants of entrepreneurs to exit even if their parent had high ability and if they can hire external managers. To see this, note that the left hand side of (38) is the sum of profit income of a low-ability entrepreneur using an external manager, his net utility from passing on the firm, and his wage income (as low ability heirs of entrepreneurs are now employed by other entrepreneurs), minus the costs for an external manager. This expression is, as in the main text, compared with $w+B$. Thus, given (38) all low-ability descendants of entrepreneurs exit, such that $n^{L}=0$. This implies $\tilde{w}\left(0, n^{H}, \tau_{k}\right)=w^{*}$ in long-run equilibrium (as in part (i) of Proposition 1 in the main text). Again, the number of exiting firms is $\left(1-p^{H}\right) n^{H}$.

Second, suppose $\Delta>\hat{\hat{\Delta}}$, which is equivalent to

$$
g\left(a^{M}, w^{*}, \tau_{k}\right)+\Delta(1-\delta) \tilde{k}\left(a^{H}, w^{*}, \tau_{k}\right)-\left(w^{*}+e\right)+w^{*}>w^{*}+B\left(\tau_{b}\right) .
$$

In this case, low-ability descendants of entrepreneurs remain in the market if their parent had 
high ability. Since $e<\hat{e}$, all of them hire external managers (recall the discussion of (36)). According to assumption (A2), they exit if their parent had low ability. The remaining results follow from the proof of part (ii) of Proposition 1.

Qualitatively, we thus get the same result as for the basic model. While very similar, results are not identical. In particular, we observe $\hat{\hat{\Delta}}<\hat{\Delta}$ because

$$
w^{*}+e-g\left(a^{M}, w^{*}, \tau_{k}\right)<w^{*}-g\left(a^{L}, w^{*}, \tau_{k}\right) \quad \Leftrightarrow \quad e<\hat{e},
$$

which is always true when there are hired managers. This means that the tax advantage that has to be granted in order for low-ability heirs to continue a firm is lower than in the basic model. In other words, with hired managers the economy is, ceteris paribus, more likely to be in a Type-2 equilibrium. Given the possibility to employ managers, low-ability types are better off and are more easily convinced by the tax system to continue a family business.

Turning towards the number of firms in equilibrium we arrive at the following result.

Proposition A.2. Given the possibility of external management and $e<\hat{e}$, the number of firms led by high-ability entrepreneurs in an equilibrium of Type 1 and Type 2 are given by

$$
\begin{aligned}
& n^{H}=\frac{1}{\tilde{l}\left(a^{H}, w^{*}, \tau_{k}\right)+1} \equiv \hat{\hat{n}}^{H 1}, \\
& n^{H}=\frac{1}{\left(1-p^{H}\right) \tilde{l}\left(a^{M}, w^{*}, \tau_{k}\right)+\tilde{l}\left(a^{H}, w^{*}, \tau_{k}\right)+1+\left(1-p^{H}\right)} \equiv \hat{\hat{n}}^{H 2},
\end{aligned}
$$

respectively, where $w^{*}$ is given by (16). In a Type 2 equilibrium there are less firms led by high-ability entrepreneurs than in a Type 1 equilibrium $\left(\hat{\hat{n}}^{H 2}<\hat{\hat{n}}^{H 1}\right)$. Unless managers and high-ability entrepreneurs display the same ability there are more firms in total in a Type 2 equilibrium.

Proof. As for the basic model, for a Type 1 equilibrium (40) follows from (17) and $n^{L}=0$ (recall part (i) of Proposition 1), where $w^{*}$ is given by (16). In Type 2 equilibrium, (17) and $n^{L}=\left(1-p^{H}\right) n^{H}$ (recall part (ii) of Proposition 1) imply

$$
n^{H}\left[\tilde{l}\left(a^{H}, w, \tau_{k}\right)+\left(1-p^{H}\right) \tilde{l}\left(a^{M}, w, \tau_{k}\right)+1+\left(1-p^{H}\right)\right]=1,
$$

which leads to (41). From (40) and (41) we find $\hat{\hat{n}}^{H 1}>\hat{\hat{n}}^{H 2}$. Moreover, in Type 2 equilibrium, where $n^{L}=\left(1-p^{H}\right) \hat{\hat{n}}^{H 2}$, the total number of firms is given by $\left(2-p^{H}\right) \hat{\hat{n}}^{H 2}$. We obtain that $\left(2-p^{H}\right) \hat{\hat{n}}^{H 2}>\hat{\hat{n}}^{H 1}$ if and only if

$$
\left(2-p^{H}\right)\left[\tilde{l}\left(a^{H}, w^{*}, \tau_{k}\right)+1\right]>\tilde{l}\left(a^{H}, w^{*}, \tau_{k}\right)+\left(1-p^{H}\right) \tilde{l}\left(a^{M}, w^{*}, \tau_{k}\right)+1+\left(1-p^{H}\right),
$$

which simplifies to $\tilde{l}\left(a^{H}, w^{*}, \tau_{k}\right)-\tilde{l}\left(a^{M}, w^{*}, \tau_{k}\right)>0$.

Thus, qualitatively, our second main result from the basic model remains also unchanged.

Welfare effects stemming from crossing the threshold between Type 1 and Type 2 equilibrium were not easily assessed analytically in the basic model. An analytical assessment is even more difficult in the extended version. Qualitatively, a crossing of $\hat{\hat{\Delta}}$ leads to the following modifications. Firms of low-ability entrepreneurs are now more productive and thus larger than in the basic model since they are led by professional managers. This makes the Type 2 equilibrium more efficient. There are, however, also two negative effects. Firms led external managers may 
not be of the same productivity as those led by high-ability entrepreneurs (firm founders). Then the crowding out effect of the basic model continues to appear (although to less drastic degree), i.e. there is less creative destruction in Type 2 equilibrium. Secondly, there occurs an efficiency loss not present in the basic model: some high-ability descendants of workers incur costs in order to become managers. These costs have to be compensated for by low-ability heirs; an effect that leads to higher production costs and a lower scale of production.

Figure 1. Management of Family Businesses
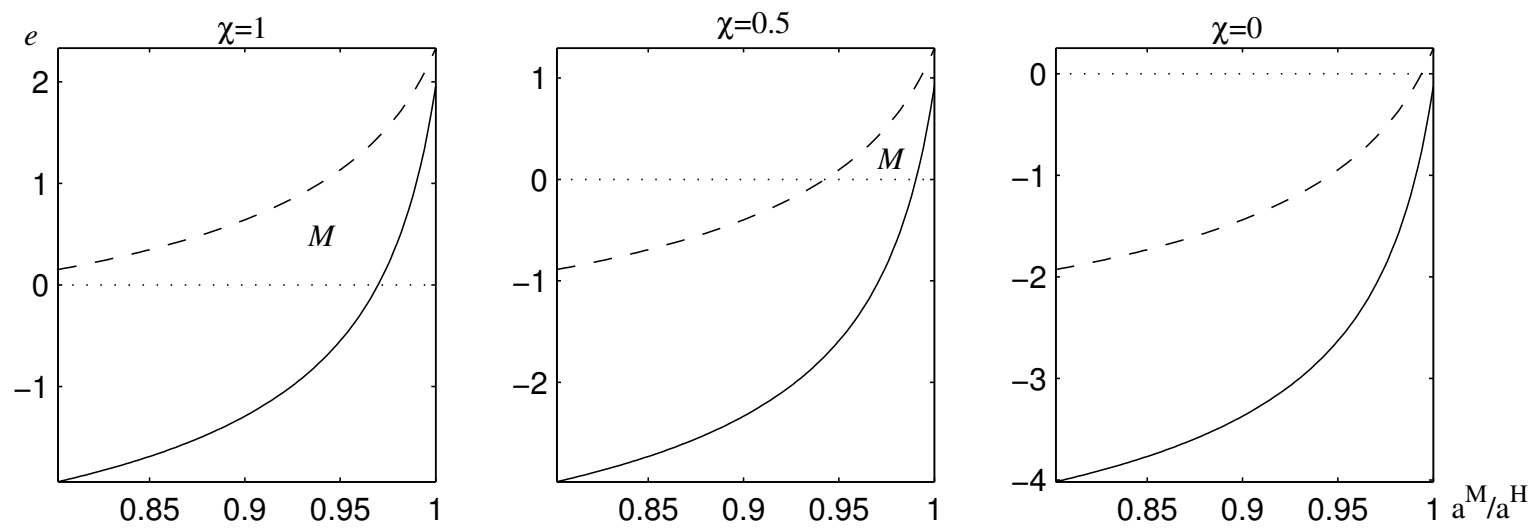

For alternative relative productivity of hired managers, $a^{M} / a^{H}$, the solid line shows the threshold above which $e$ must be for entry and exit in equilibrium. The dashed line shows the $\hat{e}$-curve, below which $e$ must be for external management to be worthwhile. In the area below the curves we find equilibria with external management and exit.

Next we evaluate how the consideration of external management modifies our quantitative results from the main text. For that purpose we take the model as calibrated for Germany in the main text and introduce the possibility of external management. We first investigate the parameter space for which there will be external management and finally assess the quantitative consequences of our most interesting policy case, the change from case 1 to case 3, i.e. from non-beneficial to beneficial tax treatment of continued family firms. The new element is now, of course, that firms of low-ability heirs are led by external managers (we focus on the case where $e<\hat{e})$.

Our first interesting observation is how little scope there is for external management. For an intuition note that in an equilibrium with exit and entry the management premium $e$ must neither be too high nor too low. If $e$ were too high, low-ability heirs of high-ability entrepreneurs would prefer selling the firm against continuing it with help of external management. On the other hand, if $e$ were too low, there would be no exit and entry in equilibrium. For given $e$, the same argument applies with respect to management quality $a^{M}$. If management quality is too low (compared with that of high-ability firm founders) heirs would always prefer to sell the firm whereas if management quality is too high, heirs would never sell a business no matter how long the series of low-ability descendants already is. Recall that - given the possibility of external management - currently about 30 percent of Germany's entrepreneurs are planning to sell their 
business. Thus an equilibrium with exit is the proper equilibrium to match even when there is external management.

Taking our benchmark calibration for Germany, Figure 1 displays the set of parameter values for management premium $e$ and relative management quality $a^{M} / a^{H}$ for which an equilibrium with management and exit exists. The solid line shows the threshold above which $e$ must be for entry and exit in equilibrium according to (A2). The dashed line shows the $\hat{e}$-curve, below which $e$ must be for external management to be worthwhile according to (36). In the area between the curves, marked by an "M", we find equilibria with external management and exit.

For a numerical assessment of the required management premium $e$ recall that income per capita was 3.22 in our benchmark calibration. Thus there will be external management only for quite modest values of manager premia. Note that the two curves intersect implying that there exists no equilibrium when family firms led by managers are supposed to have the same productivity as those led by high-ability entrepreneurs. At the highest level of feasible manager productivity $e$ is around 2 indicating that managers earn about sixty percent more than average income per capita. Against this background it can be argued that there is little scope for external management in our model. This result is well in tune with the observation that Germany's SMEs are, in fact, mostly led by entrepreneurs.

TABle 1. Consequences of Inheritance Policy: External Management

\begin{tabular}{llrr}
\hline \hline & & case 1 & case 3 \\
\hline$a^{M} / a^{H}=0.95$ & $n^{H}$ (in \%) & 7.00 & 6.37 \\
$e=0$ & $n$ (in \%) & 7.00 & 8.28 \\
& $y$ 3.22 & 3.18 \\
& $u_{\text {stay }}^{\text {high-low }}$ & 13.40 & 14.13 \\
& welfare & 9.56 & 9.51 \\
\hline$a^{M} / a^{H}=0.95$ & $n^{H}$ (in \%) & 7.00 & 6.37 \\
$e=0.5$ & $n$ (in \%) & 7.00 & 8.28 \\
& $y$ & 3.22 & 3.18 \\
& $u_{\text {stay }}^{\text {high-low }}$ & 13.40 & 13.63 \\
& welfare & 9.56 & 9.50 \\
\hline$a^{M} / a^{H}=0.99$ & $n^{H}$ (in \%) & 7.00 & 5.77 \\
$e=1.9$ & $n$ (in \%) & 7.00 & 7.50 \\
& $y$ & 3.22 & 3.21 \\
& $u_{\text {stay }}^{\text {high-low }}$ & 13.40 & 13.05 \\
& welfare & 9.56 & 9.52 \\
\hline \hline
\end{tabular}

All other parameters are taken from the benchmark model without external management as evaluated in Table 1 in the main text.

In Table 1 we reconsider the most interesting policy experiment from the main text, the introduction of preferential tax treatment of family firms contingent on their continuation, i.e. the transition from case-1 policy to case-3 policy. For the first exercise we assume external professional management is available at no extra cost (compared to workers). As shown, in equilibrium managers can then not have the same productivity as high-ability entrepreneurs. 
With $a^{M}=0.95 a^{H}$ we have assumed about the highest feasible value. We observe that the slump of income and welfare caused by a threshold crossing from case 1 to case 3 is now less drastic than for our basic model. Qualitatively, however, all our main results are still there. In line with our intuition, low-ability heirs continuing the family firm using external managers are better off when the tax system rewards continuation. Yet the crowding out effect continues to dominate. Aggregate welfare is lower for case-3 policy.

The second experiment shows that these results are unaffected when we assume a moderate wage premium for managers. The most pronounced effect is that the improvement of welfare for low-ability heirs through preferential tax treatment is much lower. Finally we assume that family firms led by external managers have almost the same productivity than those led by highability entrepreneurs, $a^{M}=0.99 a^{H}$. As shown, these managers have to be relatively expensive for an equilibrium with exit to exist. The threshold crossing now leaves income per capita indeed almost unaffected, i.e. there is almost no crowding out. Nevertheless, aggregate welfare is again lower under case 3. This effect is now mainly driven by the lower welfare of low-ability heirs who are caused to keep the business by the tax system and who have to pay for management services. 


\section{REFERENCES}

Andreoni, J., 1989, Giving with impure altruism: applications to charity and ricardian equivalence, Journal of Political Economy 97, 1447-1458.

BDI, 2006, BDI-Mittelstandspanel, Ergebnisse der Online-Mittlestandsbefragung, Bundesverband der Deutschen Industrie, Berlin.

Bennedsen, M., K.M. Nielsen, F. Perez-Gonzales, and D. Wolfenzon, 2007, Inside the family firm: the role of families in succession decisions and performance, Quarterly Journal of Economics 122, 647-691.

Bertrand, M. and A. Schoar, 2006, The role of family in family firms, Journal of Economic Perspectives 20, 73-96.

Bloom, N. and J. Van Reenen, 2007, Measuring and explaining management practices across firms and countries, Quarterly Journal of Economics, forthcoming.

Bossmann, M., C. Kleiber and K. Wälde, 2007, Bequests, taxation and the distribution of wealth in a general equilibrium model, Journal of Public Economics 91, 1247-1271.

Cagetti, M. and M. de Nardi, 2006, Entrepreneurship, frictions, and wealth, Journal of Political Economy 114, 835-870.

Cagetti, M. and M. de Nardi, 2007, Estate taxation, entrepreneurship, and wealth, NBER Working Paper 13160.

Caselli, F. and N. Gennaioli, 2006, Dynastic Management, CEP Discussion Paper 741, London School of Economics.

Deutsche Bank, 2007, Germany's Mittelstand - an endangered species?, Deutsche Bank Research, Frankfurt.

Djankov, S., R. La Porta, F. Lopez-de-Silanes, and A. Shleifer, 2002, The regulation of entry, Quarterly Journal of Economics 117, 1-37.

European Commission, 1994, Communication of the commission on the transfer of small and medium sized enterprises, Luxembourg, Office for Official Publications of the European Communities, Reference IP/94/1161.

European Commission, 2003, SMEs in Europe 2003, Luxembourg, Office for Official Publications of the European Communities.

European Commission, 2006, Business Transfers - 690,000 Companies and 2.8 Million Jobs at Stake Every Year, Memo 06/122, Brussels.

Farhi, E. and I. Werning, 2005, Inequality, social discounting and estate taxation, NBER Working Paper 11408.

Fonseca, R., P.-C. Michaud, and T. Sopraseuth, 2007, Entrepreneurship, wealth, liquidity constraints and start up costs, RAND Working Paper W-R 500. 
Gale, W.G., and M.G. Perozek, 2001, Do estate taxes reduce savings?, in: Gale, W., Hines Jr., J.R., Slemrod, J. (Eds.), Rethinking Estate and Gift Taxation, Brookings Institution Press, Washington, DC.

Gale, W.G., and J. Slemrod, 2001, Rhetoric and Economics in the estate tax debate, National Tax Journal 54, 613-627.

Galton, Francis, 1877, Typical laws of heredity, Proceedings of the Royal Institute Great Britain 8, 282-301.

Gentry, W.M., and G. Hubbard, 2004, Entrepreneurship and household saving, Advances in Economic Analysis and Policy 4, 1-55.

Grossmann, V., 2001, Inequality, Economic Growth and Technological Change: New Aspects in an Old Debate, Physika, Heidelberg.

Heer, B., 2001, Wealth distribution and optimal inheritance taxation in life-cycle economies with intergenerational transfers, Scandinavian Journal of Economics 103, 445-465.

Holtz-Eakin, D., D. Joulfaian, and H.S. Rosen, 1994, Entrepreneural survival and liquidity constraints, Journal of Political Economy 102, 53-75.

Holtz-Eakin, D., 1999, The death tax: investments, employment, and entrepreneurs, Tax Notes 782.

Holtz-Eakin, D., and D. Marples, 2001, Distortion costs of taxing wealth accumulation, NBER Working Paper 8261.

Kopczuk, W., and J. Slemrod, 2001, The impact of the estate tax on wealth and accumulation and avoidance behavior of donors, in: Gale, W., Hines Jr., J.R., Slemrod, J. (Eds.), Rethinking Estate and Gift Taxation, Brookings Institution Press, Washington, DC, pp. 299-343.

Laitner, J., 2001, Inequality and wealth accumulation: eliminating the federal gift and estate tax rate, in: in: Gale, W., Hines Jr., J.R., Slemrod, J. (Eds.), Rethinking Estate and Gift Taxation, Brookings Institution Press, Washington, DC, pp. 299-343.

Mulligan, C.B., 1999, Galton versus the human capital approach to inheritance, Journal of Political Economy S184-S224.

Pérez-González, F., 2006, Inherited Control and Firm Performance, American Economic Review 96, 1559-1588.

Prescott, E., 2006, Death and taxes, Wall Street Journal June 1, A 14.

Quadrini, V., 2000, Entrepreneurship, saving, and social mobility, Review of Economic Dynamics $3,1-40$.

Uhlig, H. and N. Yanagawa, 1996, Increasing the capital income tax may lead to faster growth, European Economic Review 40, 1521-1540.

Van Praag, M. and P.H. Versloot, 2007, What is the value of entrepreneurship? A review of recent research, IZA Discussion Paper No. 3014. 
Villalonga, B. and R. Amit, 2006, How do family ownership, management and control affect firm value? Journal of Financial Economics 80, 385-417.

Weil, D.N., 1994, The saving of the elderly in micro and macro data, Quarterly Journal of Economics 109, 55-81.

ZEW, 2004, Erbschaftssteuerbelastung in Deutschland, den Staaten der EU und anderen wichtigen Staaten bei unbeschränkter und beschränkter Steuerpflicht, Kurzfassung, Zentrum für Europäische Wirtschaftsforschung, Mannheim.

ZEW, 2005, Die Entwicklung und Verteilung des Vermögens privater Haushalte unter besonderer Berücksichtigung des Produktivvermögens, Zentrum für Europäische Wirtschaftsforschung, Mannheim. 